\title{
LA SEGUNDA FACTORÍA DE LA HABANA ANTES DE LA GUERRA DE LA INDEPENDENCIA DE LAS TRECE COLONIAS 1760-1779. UNA LECTURA DESDE EL ESTANCO ESPANONL ${ }^{1}$
}

The Second Factory of Havana before the War of Independence of the Thirteen Colonies 1760-1779. A Reading from the Spanish Estanco

Santiago de LUXÁN MELÉNDEZ

Universidad de Las Palmas de Gran Canaria

Correo-e: sluxan@dch.ulpgc.es

Montserrat GÁRATE OJANGUREN

Universidad del País Vasco

Correo-e: mariamontserrat.garate@ehu.es

RESUMEN: Nuestro principal objetivo es verificar los problemas del estanco español con relación a su principal proveedor, es decir, la Isla de Cuba. La vuelta a la administración directa por parte de la Monarquía de la producción, venta y exportación del tabaco cubano como principal proveedor del estanco metropolitano, una vez superado el accidente de la toma de La Habana por los ingleses, se vio acompañada por la expansión del cultivo en la Isla, pero no por el aumento en el largo plazo del consumo del producto en el estanco metropolitano. Tanto el tabaco de Virginia, como sobre todo el del Brasil, continuaron manteniendo una posición privilegiada en el mercado español. Por otro lado, la mayor apertura de La Habana al

1. Este trabajo se encuadra en el proyecto de investigación «La integración de las economías atlánticas: el papel del tabaco en los imperios ibéricos 1636-1832» (HAR2012-34535). 
SANTIAGO DE LUXÁN MELÉNDEZ Y MONTSERRAT GÁRATE OJANGUREN LA SEGUNDA FACTORÍA DE LA HABANA ANTES DE LA GUERRA DE LA INDEPENDENCIA DE LAS TRECE COLONIAS 1760-1779. UNA LECTURA DESDE EL ESTANCO ESPAÑOL

mercado americano coincide con la creación de los estancos en el resto de América y, por las cifras que conocemos, no parece que fuera, por lo menos hasta el período de la Guerra de la Independencia de las Trece Colonias, la solución a los problemas de exceso de producción que tendrán lugar en la Isla Antillana.

Palabras clave: Estanco del tabaco; Cuba.

ABSTRACT: Our main objective is to verify the Spanish problems of Spanish estanco relative to its main supplier, the Island of Cuba. The return to direct management by the Monarchy of the production, sale and export of Cuban tobacco as a leading provider of Metropolitan estanco, once passed the accident of taking of Havana by the English, was accompanied by the expansion of culture in the Island, but not the increase in longterm consumption of the product in the Metropolitan estanco. Two types of tobacco, the Virginian, and especially the Brazilian one, continued to maintain a privileged position in the Spanish market. On the other hand, the more opening of Havana to American market coincides with the creation of estancos in the rest of America. According to the known estimations, at least until the period of the War of Independence of the Thirteen Colonies, the solution to the problems of excess production did not take place in the Antillean Island.

Key words: The estanco of Tobacco; Cuba.

\section{INTRODUCCIÓN}

El trabajo que presentamos pretende valorar el significado de la política de corte mercantilista de Esquilache (1759-1766) con relación al tabaco. Fue precisamente él quien, al poco tiempo de ocupar la secretaría de Estado de Hacienda, rescindió el asiento de tabacos en manos de la Compañía de La Habana, para pasar a la administración directa con la creación de la Segunda Factoría en 1760. Igualmente es objeto de nuestro análisis valorar la crisis de esa política en los primeros años de la década de 1770, cuando estaba al frente de la Hacienda borbónica Miguel Múzquiz (1766-1785), quien, según se argumentaba, tendría que hacer frente al exceso de tabaco en la metrópoli y a la baja calidad del producto enviado desde La Habana. Con estos objetivos, en primer lugar estudiaremos cómo, en el contexto americano, durante aquel periodo se generalizó la fórmula del estanco y los logros que se pretendían alcanzar con la nueva administración en La Habana. En la segunda parte analizaremos la producción y exportación de tabaco desde Cuba. Las cuestiones que este apartado suscita son varias: ¿Qué tabaco 
SANTIAGO DE LUXÁN MELÉNDEZ Y MONTSERRAT GÁRATE OJANGUREN

LA SEGUNDA FACTORÍA DE LA HABANA ANTES DE LA GUERRA DE LA INDEPENDENCIA

DE LAS TRECE COLONIAS 1760-1779. UNA LECTURA DESDE EL ESTANCO ESPAÑOL

adquiría la Factoría de La Habana a los cosecheros? ¿Qué volumen se exportaba a la metrópoli? ¿Podemos conocer el total de tabaco producido en la Isla durante la Segunda Factoría? Por fin, en un tercer apartado, analizaremos hasta qué punto el tabaco antillano tenía dificultad para abastecer en régimen de exclusividad el mercado español y, asimismo, la escasa capacidad del mercado legal americano para absorber el resto de la producción.

\section{El CONTEXTO DEL MONOPOLIO DE TABACOS ESPAÑOL Y AMERICANO}

Desde la perspectiva del Imperio español tres fueron los ejes principales sobre los que se vertebra el abastecimiento de tabaco al mercado metropolitano desde la segunda mitad del xviı: En primer lugar, Virginia y Maryland-Gran Bretaña, en segundo lugar, Brasil-Portugal y, por último, La Habana-España ${ }^{2}$.

Hasta 1624 el tabaco de Virginia ni siquiera podrá competir en los puertos ingleses con el procedente de las colonias españolas. A partir de esa fecha, su presencia se hará dominante en los mercados europeos, siendo Holanda e Irlanda sus principales compradores. En torno a mediados del xviI registramos las primeras exportaciones al mercado español que pasará de recibir 3.000 libras en 1649 (Bilbao) a 1.000 .000 de libras en 1699 y 1700 , respectivamente. Estas últimas cifras no se volverán a alcanzar en la primera mitad del xvirI. Al final de la Guerra de Sucesión española, en el bienio 1713-1714, teniendo como referencia la Fábrica de Sevilla, el tabaco de La Habana significaba el 54,5\% del total de las entradas y el resto se lo repartían el de Virginia (34,1\%) y el de Brasil (11,4\%) 3 . En 1760, por ejemplo, en los libros de entrada de la Fábrica de Sevilla solamente se anotaron 537.705 libs., frente a las casi tres millones de libras de La Habana o las 68.438 libs. del Brasil ${ }^{4}$. Con relación al tabaco brasileño, después de 1700 llegaban a Lisboa más de 7.000.000 libras anuales procedentes de Bahía, es decir, la cuarta parte de la cantidad que los ingleses importaban de Chesapeake. Antes de 1700 el mercado del tabaco de Virginia (a través de los puertos ingleses, principalmente Londres) se extiende a Holanda, Irlanda, Francia, España, Alemania, Escandinavia, puertos del mar Báltico, Flandes y Rusia; este última solo aparece registrada en 1699 con

2. Gárate, M. y Luxán, S.: «Cuba y Nueva España: los dos pilares del tabaco español en el siglo XVIII», Ulúa, 14, 2009, pp. 35-74. Igualmente, LuxÁn, S. y GÁrATE, M.: «La creación de un Sistema Atlántico del Tabaco (siglos XVII-XVIII). El papel de los monopolios tabaqueros. Una lectura desde la perspectiva española», Anais del Centro de Historia de Além-Mar, 2010, XI, pp. 145-175.

3. Rodríguez Gordillo, J. M.: La difusión del tabaco en España. Diez estudios. Sevilla, Universidad de Sevilla-Fundación Altadis, 2002, pp. 137-138.

4. Luxán, S. de, Gárate, M. y Rodríguez Gordillo, J. M.: Cuba-Canarias-Sevilla. El estanco español del tabaco y las Antillas (1717-1817). Las Palmas de Gran Canaria, Ediciones del Cabildo Insular, 2012. 
SANTIAGO DE LUXÁN MELÉNDEZ Y MONTSERRAT GÁRATE OJANGUREN

LA SEGUNDA FACTORÍA DE LA HABANA ANTES DE LA GUERRA DE LA INDEPENDENCIA

DE LAS TRECE COLONIAS 1760-1779. UNA LECTURA DESDE EL ESTANCO ESPAÑOL

la importante cantidad de 1.296.000 libras; la máxima recepción de Holanda, por su parte, se registra en 1697 con 7.800 .000 libras $^{5}$. En las primeras décadas del xviII, según las cifras de Price, elaboradas a partir de los libros de aduanas de los puertos, Gran Bretaña importaba 30.000 .000 de libs./año y en vísperas de la Guerra de la Independencia de las Trece Colonias, tres veces más siendo Glasgow el puerto de recepción principal ${ }^{6}$. Todos estos datos, nos muestran la importancia relativa del mercado español respecto de las elevadas cifras de tabaco que, desde América, llegaban a puertos europeos.

Volviendo al caso español, uno de los aspectos básicos de la política de suministros del estanco español será, no solo su abastecimiento, sino la capacidad del mercado metropolitano de absorber tabaco cubano. Si en su origen, el planteamiento al establecerse el estanco en Cuba se había concebido a este como el gran abastecedor y casi único de España y sus colonias ¿̇cómo se puede entender que los tabacos de otro origen -Virginia y Brasil- accedieran, casi siempre por la vía de asientos, al mercado español y ocuparan casi el 50\% del abastecimiento? ${ }^{7}$ Llegados a este punto, la propia política económica que se estaba llevando a cabo estaba impidiendo la consolidación de La Habana como el abastecedor único. El cuadro siguiente es suficientemente significativo y explica, en parte, las dificultades españolas por convertir a Cuba, especialmente desde la creación de la Segunda Factoría en 1760, en abastecedor único del monopolio español, como era el deseo de Esquilache.

5. Los datos proceden de los libros de las aduanas portuarias, recopilados de manera muy agregada en Gray, S. and Wyckoff, V. J.: «The international Tobacco Trade in the Seventeenth Century», The Southern Economic Journal, 1940, pp. 1-26. En 1701-1702, que es cuando termina la información de estos historiadores, España no es contabilizada en las salidas de los puertos británicos.

6. Price, J. M.: France and the Chesapeake. A History of the French Tobacco Monopoly, 16741791, and of Its Relationship to the British and American Tobacco Trades. An Arbor, The University of Michigan Press, 1973, p. 588.

7. Sobre del tabaco Brasil en España, Torres SÁnchez, R.: «Capitalismo internacional y política estatal. Los asientos del tabaco en España durante la segunda mitad del siglo XviII», en GonZÁLEZ Enciso, A. y Torres Sánchez, R. (eds.): Tabaco y Economía en el siglo XVIII. Pamplona, Eunsa, 1999, pp. 415-456; sobre la reexportación del tabaco de Virginia y Maryland, García Fernández, M. N.: Comerciando con el enemigo: el tráfico mercantil anglo-español en el siglo XVIII (1700-1765). Madrid, CSIC, 2006, pp. 211-216. Igualmente Rodríguez Gordillo, J. M.: «La influencia del tabaco de Virginia en la configuración del mercado español en la segunda mitad del siglo xviI», en Vila Vilar, E. y Lacueva Muñoz, J. (coords.): Mirando las dos orillas: intercambios mercantiles, sociales y culturales entre Andalucía y América. Sevilla, Escuela de Estudios Hispano Americanos, 2012, pp. 227-249. 
SANTIAGO DE LUXÁN MELÉNDEZ Y MONTSERRAT GÁRATE OJANGUREN LA SEGUNDA FACTORÍA DE LA HABANA ANTES DE LA GUERRA DE LA INDEPENDENCIA DE LAS TRECE COLONIAS 1760-1779. UNA LECTURA DESDE EL ESTANCO ESPAÑOL

Cuadro 1. Tabaco importado de Cuba (Cádiz) y Brasil (Lisboa) y las Trece Colonias 1760-1805 en libs.

\begin{tabular}{|c|c|c|c|}
\hline Quinquenios & Cuba-Cádiz & Bahía-Lisboa & Trece Colonias - Gran Bretaña \\
\hline $1760-64$ & $1,212,531$ & 6.663 .300 & 81.504 .200 \\
\hline $1765-69$ & $2,435,402$ & 6.545 .775 & 72.223 .200 \\
\hline $1770-74$ & $4,667,440$ & 5.647 .325 & 95.580 .800 \\
\hline $1775-79$ & $2,289,093$ & 8.936 .975 & 29.617 .800 \\
\hline $1780-84$ & $1,890,799$ & 11.107 .225 & 47.263 .000 \\
\hline $1785-89$ & $3,257,870$ & 9.043 .375 & \\
\hline $1790-94$ & $2,323,038$ & 9.844 .575 & \\
\hline $1795-99$ & 731,21 & 11.269 .325 & \\
\hline $1800-04$ & 953,336 & 12.246 .325 & \\
\hline
\end{tabular}

Fuente: Náter (2000), Fernández Pinedo (2002), Nardi (1991) y Price (1973)8.

Terminada la Guerra de la Oreja de Jenkins (1739-1746), la extensión de la fórmula del estanco a los Reinos de las Indias por la Monarquía española puede ser considerada como parte básica de una nueva estrategia de defensa global del Imperio. Antes de la Paz de París de 1763, se crea el estanco en el Perú, que tarda en consolidarse, puesto que, aunque su establecimiento es ordenado por la Corona en 1745, y su proceso de creación se inicia en 1752, no alcanzará su culminación hasta que el conde de Superunda promulgue sus ordenanzas en $1759^{9}$. En aquellos momentos

8. NÁter VÁzquez, L.: Integración imperial: el sistema de monopolios de tabaco en el Imperio español. Cuaba y América en el siglo XVIII. Tesis doctoral inédita, México, Centro de Estudios Históricos de El Colegio de México, 2000; Fernández de Pinedo, N.: Comercio exterior y fiscalidad: Cuba (1794-1860). Bilbao, Universidad del País Vasco, 2002; NArdi, J. B.: Le Tabac brésilien et ses fonctions dans l'ancien système colonial portugais: 1570-1830. Marsella, 1991; PRICE, J. M. (1973), p. 588.

9. Sobre esta renta el estudio clásico de Céspedes del Castillo, G.: «La Renta del tabaco en el virreinato del Perú», Revista Histórica, 21, 1954, pp. 138-163; el de Hunnefeldt, Сн.: «Etapa final del monopolio en el Virreinato del Perú: el tabaco de Chapapoyas", en Jacobsen, N. y Pulhe, H. J. (eds.): The Economies of Mexico and Peru during the Late Colonial Period. Berlín, Colloquium Verlag, 1986, pp. 388-417; el de Fisher, J. R.:«El estanco del tabaco en el Perú borbónico», en González Enciso y Torres Sánchez (eds.): Tabaco y Economía en el siglo XVIII, 1999, pp. 31-53; o el de Vizcarra, C.: Markets and Hierarchies in Late Colonial Spanish America: The Royal Tobacco Monopoly in the Viceroyalty of Perú 1752-1813. Tesis de doctorado, University of Illinois at Urbana-Champaing, 2001. 
SANTIAGO DE LUXÁN MELÉNDEZ Y MONTSERRAT GÁRATE OJANGUREN

LA SEGUNDA FACTORÍA DE LA HABANA ANTES DE LA GUERRA DE LA INDEPENDENCIA

DE LAS TRECE COLONIAS 1760-1779. UNA LECTURA DESDE EL ESTANCO ESPAÑOL

el virreinato abarcaba la Capitanía General de Chile, Paraguay y el territorio de La Plata. Es más importante desde la perspectiva metropolitana, sin embargo, la refundación de la Factoría de La Habana (1760), que significaba la implantación de la administración directa por cuenta de la Hacienda Real en un intento de intensificar el monopolio, pero también de incrementar la dimensión interamericana de La Habana, impidiendo la salida clandestina del tabaco ${ }^{10}$. Entre La Paz de París (1763) y la Guerra de Independencia de las Trece Colonias (1779-1783), teniendo a José de Gálvez como protagonista e inductor principal de esta política, surgirán los nuevos estancos $^{11}$ de Santo Domingo (Real Orden de 12-X-1763) ${ }^{12}$, Nueva España $(1764)^{13}$, Capitanía de Guatemala y Virreinato de Nueva Granada $(1766)^{14}$.

10. LuxÁn, S. de y Gárate, M.: «El proceso de instauración de la segunda factoría en Cuba (1760-1766)», en González Enciso, A. (ed.): Política económica y gestión de la Renta del Tabaco en el siglo XVIII. Madrid, Fundación Altadis, 2008, pp. 211-281. Igualmente, LuXÁN, S. de, GÁrATE, M. y RodRíGuez GordiLlo, J. M. (2012).

11. Escobedo, R.: «La expansión geográfica de la Renta del Tabaco», Estudis, 33, Valencia, 2007, pp. 193-224; Luxán, S.: «La defensa global del Imperio y la creación de los monopolios fiscales del tabaco americanos en la segunda mitad del siglo xviII», en Luxán, S. (ed.), Política y hacienda del tabaco en los Imperios Ibéricos (siglos XVII-XIX). Madrid, Centro de Estudios Políticos y Constitucionales, 2014, pp. 177-229.

12. Gutiérrez Escudero, A.: «Tabaco y algodón en Santo Domingo, 1731-1795», en Sarabia, J. y otros: Entre Puebla de los Ángeles y Sevilla. Sevilla, 1987; del mismo autor, «El tabaco en Santo Domingo y su exportación a Sevilla (época colonial)», en ViLA, E. y Kuethe, A.: Relaciones de poder y comercio colonial. Sevilla, 1999, pp. 117-142; del mismo autor, «Tabaco y desarrollo económico en Santo Domingo", Anuario de Estudios Americanos, 58, 2001, pp. 713-736; igualmente, Lluberes Navarro, A.: «Tabaco y catalanes en Santo Domingo durante el siglo xviII», EME, V:28, Santiago (República Dominicana), 1997, pp. 13-26.

13. Priestley, H. I.: José de Gálvez, visitor-general of Nerw Spain 1765-1771. Berkeley, 1916. McWaters, D. L.: The Royal Tobacco Monopoly in Bourbon Mexico 1764-1810. University of Florida, (Tesis doctoral), 1979; Roos, M. A.: La producción cigarrera a finales de la Colonia. La Fábrica de México. México, INAH, 1983; Rivera, J. C. y Castro, E. C.: «El Real Estanco del Tabaco en Nueva España», en Amerlinck, M. y otros: Historia y cultura del tabaco en México. México, 1988, pp. 105-126. Dean-Smith, S.: «The Money Plant: The Royal Tobacco Monopoly of New Spain 1765-1821», en Jacobsen, N. y Pulhe, H. J. (eds.): The Economies of Mexico and Perú during de late Colonial Period 1760-1810. Berlín, Colloquium Verlag, 1986, pp. 361-387; de la misma autora, Bureaucrats, Planters and Workers. The Making of the Tobacco Monopoly in Bourbon Mexico. Austin, University of Texas Press, 1992; e igualmente: «El Estanco del Tabaco en el México Borbónico», en González Enciso, A. y Torres, R. (eds.): Tabaco y economía en el siglo XVIII. Pamplona, Eunsa, 1999, pp. 79-106. CÉspedes, G.: El tabaco en Nueva España. Madrid, Real Academia de la Historia 1992; SuÁrez ArgüEllo, C. E. (1997): «De mercado libre a monopolio estatal: la producción tabacalera en Nueva España, 1760-1800» en Long Towell, J. y Attolini Lecón, A. (coords.), Caminos y mercados de México. México, Instituto de Investigaciones Históricas de la Universidad Nacional Autónoma de México-Instituto Nacional de Antropología e Historia, 2009, pp. 411-432.

14. Fallas Barrantes, M.: La Factoría de Tabacos de San José de Costa Rica. San José, Editorial de Costa Rica, 1972; Wortman, M. L.: Government and Society in Central American 1680-1840. Nueva York, Columbia University Press, 1982; Luján MuÑoz, J.: «El Establecimiento del estanco del Tabaco", Mesoamérica, 41, 2001, pp. 99-136; Harrison, J. P.: The Colombian Tobacco Industry from Governement Monopoly to Free Trade 1778-1870. Disertación Doctoral, Universidad de California, 
SANTIAGO DE LUXÁN MELÉNDEZ Y MONTSERRAT GÁRATE OJANGUREN

LA SEGUNDA FACTORÍA DE LA HABANA ANTES DE LA GUERRA DE LA INDEPENDENCIA

DE LAS TRECE COLONIAS 1760-1779. UNA LECTURA DESDE EL ESTANCO ESPAÑOL

Al borde la declaración de independencia de las Trece Colonias y durante el propio conflicto, culminará el desenvolvimiento institucional de los monopolios coloniales, con la creación del de Venezuela $(1777)^{15}$, y el del Virreinato del Plata $(1778)^{16}$. Finalmente, durante la propia Guerra y en años inmediatamente posteriores, anotamos la adquisición de personalidad propia por parte de Costa Rica ${ }^{17}$, Filipinas (1782), Luisiana (1783), Puerto Rico $(1785)^{18}$ y, por último, Chile con carácter independiente $(1786)^{19}$, culminando un largo proceso, no exento de dificultades.

\section{LA puesta en marcha de la Segunda factoría en La Habana}

A esta Joya preciosa de la Monarquía la hace resplandecer más lo exquisito de sus tabacos que alimenta y da con ellos créditos y valores a la Renta más apreciable y rica de la Corona». (Nuevo sistema político y económico para la compra de tabacos

1951. Sierra, L.: «Origen del Monopolio del tabaco» en El tabaco en la economía colombiana del siglo XIX, Bogotá, Universidad Nacional de Colombia, 1971. El capítulo dedicado a los orígenes en: www. revistas.unal.edu.co/index.php/revistaun/article [consultado el 7 de diciembre de 2013]; GonZÁlez, M.: «El estanco colonial del tabaco», Cuadernos colombianos 8, 1975, pp. 637-707. Laviana Cuetos, M. ${ }^{a}$ L.: «La renta del tabaco en el Guayaquil colonial», Revista Ecuatoriana de Historia Económica 9, 1994, pp. 13-136.

15. Arcila Farías, E.: Historia de un Monopolio. El Estanco del Tabaco en Venezuela (17791833).Caracas, 1977; Pierson, W. W.: «La Intendencia de Venezuela en el régimen colonial», Boletín de la Academia Nacional de la Historia, XXIV:95, 1941, pp. 259-275; Zubiri Marin, M. T.: «Un producto americano y su repercusión en la economía venezolana del s. xviII: el tabaco», Boletín Americanista, 1989, pp. 265-275; Lucena SAlmoral, M.: «Las dificultades de la agricultura comercializable caraqueña a fines del régimen español y la necesidad de una reforma». Quinto Centenario. Revista Complutense de Historia de América, 4, 1982, pp. 15-48.

16. Arias Divito, J. C.: «Dificultades para establecer la Renta del Tabaco en Paraguay», en Anuario de Estudios Americanos, 33, 1976, pp. 1-17; del mismo autor, «Establecimiento de la Renta de Tabacos y Naipes en el Virreinato del Río de La Plata 1778-1781», Historiografía Rioplatense, 1, 1978, pp. 7-56; CoOney, J.: «Fraude y burócratas: tabaco y Paraguay 1789-1790», Revista Paraguaya de Sociología, 29:85, 1992, pp 29-40; del mismo autor, «La Dirección General de la Real Renta de Tabacos and the Decline of the Royal Tobacco Monopoly in Paraguay», Colonial Latin American Historical Review, 1:1, 1992, pp. 101-115; Whigham, T. L.: "Agricultura and the Upper Plata: the Tobacco Trade 1780-1865", Business History Review, 59:4, 1985, pp. 563-596.

17. En el caso de Costa Rica en 1782 se crea la Factoría. El tabaco se había estancado para toda la Capitanía de Guatemala desde 1766. Fallas Barrantes, 1972.; Acuña Ortega, V.: «Historia Económica del tabaco en Costa Rica, época colonial», Anuario de Estudios Sociales Centro Americanos, San José Instituto de Investigaciones Sociales de la Universidad de Costa Rica, 4, 1978, pp. 278-392; Rico Aldave, J.: La Renta del Tabaco en Costa Rica (1766-1860). Universidad Pública de Navarra, Tesis doctoral, 2008.

18. Torres Ramírez, B.: «D. Jaime O’Daly: propulsor del cultivo del tabaco en Puerto Rico», Revista del Instituto de Cultura Puertorriqueña, núm. 15, San Juan de Puerto Rico, 1962, pp. 49-52.

19. STAPFF, A.: «La renta del tabaco en el Chile de la época virreinal. Un ejemplo de la política económica mercantilista», Anuario de Estudios Americanos, 18, 1961, pp. 1-63; Villalobos, S. y SAgrado, R.: Los estancos en Chile. Santiago de Chile, Fiscalía Nacional Económica y Centro de Investigación Diego Barros, 2004. 
SANTIAGO DE LUXÁN MELÉNDEZ Y MONTSERRAT GÁRATE OJANGUREN LA SEGUNDA FACTORÍA DE LA HABANA ANTES DE LA GUERRA DE LA INDEPENDENCIA DE LAS TRECE COLONIAS 1760-1779. UNA LECTURA DESDE EL ESTANCO ESPAÑOL

y sus preparaciones en la Isla de Cuba hasta su remisión a España, Madrid 17 de diciembre de 1782$)^{20}$.

Existió una relación directa en Cuba, entre la nueva administración del tabaco, las reformas fiscales (establecimiento de la alcabala), el nuevo régimen de comercio de 1765 (libertad de comercio) y la reorganización de la defensa. Las exigencias del programa de defensa fueron tan cuantiosas que llevaron a plantear un nuevo «Pacto colonial», entre la Corona y los criollos. Como consecuencia de este pacto se liberalizó el comercio del azúcar, aguardiente y miel de caña, junto con la importación de esclavos, a cambio de una refundición de los derechos de estos productos. Pero, frente a estas medidas «liberalizadoras», Madrid no se planteó en ningún momento la desaparición del monopolio del tabaco ${ }^{21}$.

Cuba había sido, desde finales del siglo xvir, el principal apoyo del estanco del tabaco español. Incluso, cabe destacar que la constitución de la Segunda Factoría estaba en marcha antes de la toma de La Habana por los ingleses (1762-1763) ${ }^{22}$ (episodio considerado como un accidente fatal y extraordinario ${ }^{23}$ ). Y así, la finalidad de establecer de nuevo la administración directa de la compra del tabaco fue clara: incrementar los ingresos y ayudar a la mejor defensa del Imperio.

El reinado de Carlos III, con el marqués de Esquilache como responsable de Guerra y Hacienda, comenzó con un giro importante en la orientación de la política tabaquera ${ }^{24}$. Se pretendía, en primer lugar, a) el fomento de la producción en Cuba, con el fin de desplazar al tabaco de Brasil y Virginia en el mercado español; b) mejorar la calidad, algo que se demandaba continuamente desde la Fábrica de Sevilla, a la que se dotó de un nuevo sistema de funcionamiento (Ordenanzas de 1761). En segundo lugar, se consideraba necesaria la puesta en valor del Oriente de la Isla. Además, y en tercer lugar, la nueva administración debería adquirir la totalidad de la cosecha, evitando de esta manera los manejos fraudulentos. Pero, para poder realizar estos propósitos era obligado organizar de modo eficiente la nueva institución y contar con una financiación estable y segura. Con relación a la nueva Factoría, de nada valía cambiar la administración si se elegía mal a los

20. Archivo General de Indias [en adelante AGI], Santo Domingo, leg. 2017.

21. Kuethe, A. J.: Cuba 1753-1815. Knoxville, The University of Tennesse Press, 1986, pp. 68-69.

22. Con relación al tabaco, los ingleses se apropiaron de 1.923.754 libras. AGI, Santo Domingo, leg. 2017.

23. AGI, Santo Domingo, leg. 2017, Manifiesto sobre las siembras. Madrid 17-XII-1782.

24. LuXán, S. de y Gárate, M.: «El proceso de instauración...», op. cit. y Torres, R.: «La política económica de la Renta del tabaco con el Secretario de Hacienda Miguel Muzquiz (1766-1785). La crisis de un sistema», en González Enciso, A. (ed.): Política económica y gestión de la Renta del Tabaco en el siglo XVIII. Madrid, Fundación Altadis, 2008, p. 286. 
SANTIAGO DE LUXÁN MELÉNDEZ Y MONTSERRAT GÁRATE OJANGUREN

LA SEGUNDA FACTORÍA DE LA HABANA ANTES DE LA GUERRA DE LA INDEPENDENCIA

DE LAS TRECE COLONIAS 1760-1779. UNA LECTURA DESDE EL ESTANCO ESPAÑOL

funcionarios. Respecto a la financiación, era necesario el incremento del situado de la Nueva España y, sobre todo, una mayor regularidad ${ }^{25}$.

La Real Instrucción de 7 de junio de 1760, promovida por Esquilache, tenía como principal objetivo el restablecimiento de la Real Factoría de tabaco en La Habana para la compra de tabacos cubanos y su venta en España y otros lugares del continente americano ${ }^{26}$. La nueva ordenanza pretendía que estos cambios, que debían redundar en una mayor producción y en un incremento de la calidad -algo que no había logrado la Real Compañía de La Habana- se realizasen con la aceptación máxima posible de los cultivadores, es decir, que «los labradores y cosecheros de la isla vivan tranquilizados y con más satisfacción». Siguiendo este propósito, cuando el nuevo gobernador y capitán general, Juan de Prado ${ }^{27}$, desembarcó en Santiago de Cuba, antes de hacer su entrada en La Habana, lo primero

25. Hasta 1768 (500.000 pesos) las entradas fueron muy irregulares. Cfr. AGI, Cuba, leg. 1219 y Santo Domingo, leg. 2018.

26. Archivo General de Simancas [en adelante AGS], Secretaría y Superintendencia de Hacienda [en adelante SSH], 1850: Instrucción que se forma de Orden de S.M. para el establecimiento de la Factoría del Tabaco en La Habana, que se ha de servir de cuenta de la Real Hacienda y facilitar los posibles alivios al común de los labradores y cosecheros de esta especie con mayor perfección de su cultivo y fomento de siembras (Madrid 7-VI-1760). Estas Instrucciones se recuperaron por Real Orden de 26-VIII-1783 y comunicadas por el conde de Gausa al marqués de Sonora para mejorar el abandono con el que se había manejado la Real Factoría.

27. AGI, Ultramar 233. Juan de Prado Mallesa, Portocarrero y Luna, Mariscal de Campo, Gobernador y Capitán General de La Habana, Superintendente General de la Cruzada (1761), cesó en su manejo el 30-VIII-1762 con motivo de la toma de La Habana por la nación británica. Para nuestro estudio son especialmente relevantes los volúmenes $2^{\circ}$ y $3^{\circ}$ de la Historia de la Isla de Cuba de Jacobo de la Pezuela, editados en Madrid en 1868 y 1878, respectivamente, así como el Diccionario Geográfico Estadístico Histórico de la Isla de Cuba del mismo historiador publicado en Madrid, Imprenta del Banco Industrial y mercantil, 1863-1867. En el t. II de la Historia de Cuba... pp. 448-495 hay información sobre su gobierno y una escueta biografía en el t. IV del Diccionario... pp. 277-278. En esta última obra se define a Prado como «militar disciplinista (sic) y de valor, más sin inspiración» (la cita es de la p. 474). Partió de Cádiz en la fragata San Cristóbal de la Real Compañía de La Habana el 24-XI-1761 con la misión de poner a punto la defensa de la Isla, pues España iba a entrar en la Guerra de los Siete Años (17-I-1762). Según Jacobo de la Pezuela, puso en exceso todo su celo en reformar el monopolio del tabaco que era otro de sus cometidos, desplazando a la Real Compañía de La Habana «a la que había que despojar de sus atribuciones en el ramo de tabacos y conferírselo por cuenta de la Hacienda a una Factoría General de nueva planta». Bucareli se encargaría más tarde, en el Informe que presentó al final de su mandato (12-IV-1770), de explicar las reformas que sobre el tabaco emprendió el gobernador Prado. La imagen que nos ha llegado de este personaje es, sin embargo, la del militar que perdió la joya de las Antillas ante el empuje británico. Nos interesa destacar que en la Junta de Guerra que se formó en La Habana para preparar la resistencia contra los ingleses participó el entonces «decrépito y achacoso» teniente general conde de Superunda -fundador del estanco del tabaco en el Perú- al que sorprendió la caída de La Habana en el tránsito hacia la metrópoli. Al regresar a Cádiz después de la entrega de La Habana fue sometido, junto a Prado, a un duro proceso que instruyó con severidad el conde de Aranda. El expediente del juicio fue publicado en Madrid por la Imprenta de Juan de San Martín 1773-1774 y en las Memorias de los Amigos del País de La Habana (1838). 
SANTIAGO DE LUXÁN MELÉNDEZ Y MONTSERRAT GÁRATE OJANGUREN

LA SEGUNDA FACTORÍA DE LA HABANA ANTES DE LA GUERRA DE LA INDEPENDENCIA

DE LAS TRECE COLONIAS 1760-1779. UNA LECTURA DESDE EL ESTANCO ESPAÑOL

que hizo fue recabar informes sobre la ampliación de las vegas de tabaco ${ }^{28}$. Con relación a la mejora del producto cubano, es esclarecedor el informe que Esquilache recibió de la Fábrica de Sevilla (junio de 1761), en el que, entre otras cosas, se insistía en la necesidad de armonizar conocimientos y técnicas entre Sevilla y La Habana, en la regulación de la producción de los molinos, lo que llevaba aparejado su reducción, y en el interés en conseguir una mayor aportación de tabaco en rama ${ }^{29}$. El cambio de Prado por Ricla ${ }^{30}$ en el Gobierno de la Isla y de la Factoría sirvió para reforzar las intenciones de Esquilache:

Con la paz de 1763 volvió la Plaza a la dominación del Rey y pasó a entregarse de ella el Sor conde de Ricla, como gobernador y capitán General de toda la Isla. Uno de los encargos más recomendables que llevó y se le hizo, por Rl Orden de 26 de marzo del mismo año, fue la de la compra de tabacos. Se le instruyó por el Ministerio de todo lo ocurrido anteriormente en este negocio, que su principal atención la había de poner en animar a los labradores a copiosas siembras, perfección en su beneficio, comprando todo el que produjese la mata de medio pie para arriba, por ser este aliciente el más eficaz para que se dedicasen al cultivo, con prevención expresa que si considerase necesario otros auxilios los practicase ${ }^{31}$.

Se pretendía igualmente mitigar la subordinación de toda la Isla al exclusivismo comercial del puerto de La Habana. Los tabacos del Oriente de la isla-leemos en una representación del Cabildo de Santiago de Cuba de 20-I-1787- son de calidad superior a todos los demás. La fatal desgracia que puso en manos de los ingleses el puerto de La Habana en 1762 -continuamos leyendo- permitió que

28. Parcero, M. ${ }^{a}$ C.: La pérdida de La Habana y las reformas borbónicas en Cuba, 1760-1773. Ávila, Junta de Castilla y León, 1998, pp. 41-42 y 54-55.

29. AGS, SSH, 1837: Informe de Antonio Aguilar de Cela (vecino de la cindad de Sevilla), fiel de las Reales Fábricas de Sevilla sobre la compra de tabacos de la Habana para las fábricas de Sevilla al marqués de Esquilache (30-VII-1761). Esta armonía no se consiguió y la Fábrica de Sevilla amenazó con cesar sus labores por la falta de tabacos de calidad en un Informe presentado el 24-III-1767 (Cfr. AGI, Santo Domingo, leg. 2017).

30. Ambrosio Funes de Villalpando Abarca de Bolea, Grande de España, Gentil Hombre de Cámara de SM, de la Real Orden de San Genaro, Comendador de Santiago y Teniente General de los Reales Ejércitos y conde de Ricla, fue gobernador y capitán General entre 1763-1765. En las Juntas de la Factoría aparece registrado como «encargado por comisión del mando supremo de toda la Isla de Cuba, su Capitanía General y el Gobierno de esta Plaza» (AGS, SSH, leg. 1838). Llegó a La Habana con la imposible misión de realizar «una reparación breve y completa de los desaciertos y desidias de dos siglos». La prioridad, desde luego, la tuvo la reconstrucción de las instalaciones militares que hicieran imposible una nueva ocupación. La necesidad de sufragar los gastos de guerra ante la insuficiencia de los situados, obligaron al aragonés a poner en marcha la reforma de la Hacienda centralizando sus recursos con el apoyo de la intendencia, institución que entonces se creaba en la Isla. Sobre las bases heredadas de Prado, su actuación fue decisiva en la puesta en marcha de la $2^{\mathrm{a}}$ Factoría. Pezuela define su carácter moldeado por «la paciencia, moderación y espíritu conciliador» (Historia de Cuba..., t. III, 1878, p. 57).

31. AGI, Santo Domingo, leg. 2017, Manifiesto sobre las siembras, Madrid 17-XII-1782. 
SANTIAGO DE LUXÁN MELÉNDEZ Y MONTSERRAT GÁRATE OJANGUREN

LA SEGUNDA FACTORÍA DE LA HABANA ANTES DE LA GUERRA DE LA INDEPENDENCIA

DE LAS TRECE COLONIAS 1760-1779. UNA LECTURA DESDE EL ESTANCO ESPAÑOL

los producidos por esta región se enviaran en derechura a Sevilla. Esta salida directa sería más adelante confirmada por la Real Cédula de 20-VI-1766 que, sin embargo, quedó sin cumplimiento. Unos años después, en 1775, un nuevo intento, también impulsado por parte del Cabildo de Santiago de Cuba, sería igualmente abortado. Después, en 1787 , la solicitud cabildicia ya no será el comercio directo, sino la creación de una segunda factoría, con sede en Santiago de Cuba, con total independencia de la de La Habana ${ }^{32}$.

La decisión de la Corte era que las compras de tabaco en Cuba abarcasen la totalidad de la cosecha anual, para evitar perjuicios a los cosecheros que no son, en general, los que solicitan permisos para la exportación «y si particulares negociantes al cambio de géneros, a los que dan mucha más estimación que la que tendrían a dinero efectivo, y fijando a los tavacos un precio muy moderado». Esquilache era consciente de los problemas que había ocasionado el establecimiento de la Primera Factoría en 1717, e insistirá explícitamente en la buena disposición con que se debían recoger las peticiones de los cultivadores ${ }^{33}$. Como ponen de manifiesto los primeros informes de la reforma emprendida en la administración de los tabacos, se trataba, en esta nueva etapa de la Segunda Factoría, de armonizar los intereses tabaqueros, con la presencia creciente que iría adquiriendo el azúcar ${ }^{34}$.

Tanto Ricla (1763-1765), como Bucareli (1766-71), gobernaron como superintendentes la Factoría del tabaco en una fase expansiva de la producción, tratando de fomentar el cultivo mediante la introducción de negros y un pago ajustado de los situados procedentes de México que, tras la Paz de Versalles (10-II-1763), reinició el marqués de Cruillas.

Tras la caída de Esquilache, la asunción por Múzquiz de la máxima responsabilidad de la Hacienda (1766-1785), se tradujo en lo concerniente al tabaco -en que

32. AGS, SSH, leg. 1852. CFr. GÁrate, M. y Luxán, S.: «Tabaco y política económica en Cuba a finales del siglo xviII», en González Enciso, A. (ed.): Política económica y gestión de la Renta del Tabaco en el siglo XVIII, Fundación Altadis-Ediciones El Umbral, Madrid 2008, pp. 341-371. El texto de la Solicitud del Cabildo, Justicia y Regimiento de Cuba de una factoría de tabaco independiente de la Habana, en AGS. SSH, leg. 1852, reproducido en LuXán, S. de, Gárate, M. y RodrígueZ Gordillo, J. M.: Cuba-Canarias-Sevilla, op. cit., pp. 416-424.

33. AGS, SSH, leg. 1837: oficio dirigido a Juan de Prado, gobernador de La Habana por Esquilache (Madrid 20-VII-1761) en respuesta a otro de 5-III. Sucesivos bandos de los gobernadores de 1763 y 1771, reiterarán la obligación de los cultivadores de tabaco de vender toda la cosecha a la Factoría.

34. AGS, SSH, leg. 1837. Informe de Antonio Aguilar de Cela a Esquilache (30-VII-1761); este último, escribía que no había relación directa entre la desidia a la que había llegado la siembra y el cultivo de las cañas de azúcar y el cultivo del tabaco. La Isla tenía sitio de sobra para ambos géneros. Gárate, M. y LuXán, S.: «Ilustración y reformismo económico en América durante el reinado de Carlos III (Tabaco y Hacienda)», en Astigarraga, J.; López Cordón, M. V.a y Urkía, J. M. (eds.): Ilustración, Ilustraciones. San Sebastián, Real Sociedad Bascongada de Amigos del País-Sociedad Estatal de Conmemoraciones Culturales, 2009, vol. II, pp. 485-510. 
SANTIAGO DE LUXÁN MELÉNDEZ Y MONTSERRAT GÁRATE OJANGUREN

LA SEGUNDA FACTORÍA DE LA HABANA ANTES DE LA GUERRA DE LA INDEPENDENCIA

DE LAS TRECE COLONIAS 1760-1779. UNA LECTURA DESDE EL ESTANCO ESPAÑOL

la gestión en América pasaba a ser responsabilidad del secretario del Despacho de Indias (RD de 7-V-1766) ${ }^{35}$ - en una mirada muy crítica sobre el funcionamiento de la factoría habanera:

Procuré tomar conocimiento de el (sic) estado que tenían las rentas y cuando creía que la del tabaco se hallase floreciente con aumento de sus regulares valores, en que nada se grava al vasallo, porque dimanan del gusto de cada uno en el consumo de esta especie; bien lejos de esto, encuentro considerable decadencia de sus productos, lo que me ocasionó la correspondiente displicencia, sin poder atribuir tan notable desfalco a la introducción de tabacos de contrabando ${ }^{36}$.

El problema, como en 1760, volvía a situarse en la mala calidad de la rama y el polvo acarreados desde Cuba. La solución había que seguir buscándola en el control a través de las visitas y reconocimientos de las vegas, estimulando su cultivo y cuidado «inspirando a los labradores un espíritu de gloriosa vanidad», para que evitasen separar de sus cosechas porción alguna del producto más selecto. Igualmente, había que advertir a los dependientes de los molinos para que pusiesen el mayor «conato» en las mezclas, beneficios, molido y cernido «de suerte que merezcan el aprecio de S.M. -al que se situaba como máximo juez- por su primorosa calidad y fragancia».

Si a los ojos de la Renta La Habana era culpable ${ }^{37}$, no menos lo era Sevilla, desde la perspectiva cubana, que no acertaba a elaborar el producto. El nuevo administrador Echeverría ${ }^{38}$ enumeraba, en defensa de la Factoría, los esfuerzos

35. AGI, Indiferente General, leg. 1745. En 26 de mayo de 1766, se notificaba a José de Gálvez, entonces Visitador General en Nueva España, la nueva providencia de SM para que todas las órdenes de la Renta del Tabaco en las Américas se expidieran por el Ministerio de Indias con acuerdo del de Hacienda.

36. AGS, SSH, leg. 1838: de Múzquiz a Rapún (Aranjuez 20-VI-1766).

37. Los informes de la Fábrica de Sevilla que dan para 1770 un volumen de tabaco almacenado de 10.615.252 libs. de mala calidad son contundentes. AGI, Santo Domingo, leg. 2017, Manifiesto sobre las siembras. Madrid 17-XII-1782.

38. Martín Javier de Echeverría fue administrador de la Factoría de tabacos de Cuba entre 1764 y 1787 en que falleció. Partió de Cádiz en Noviembre de 1764 (AGS, SSH, leg. 1838: Carta de Martín de Echevarría a Esquilache (Cádiz, 23-X-1764)); fue suspendido de empleo y sueldo entre 1778-1783, recuperando el cargo a partir de la reorganización de la Factoría en 5-XI-1783. Según la Instrucción de 26-VIII-1783 enviada al Intendente Juan Ignacio Urriza, para que se hiciese cargo de la Superintendencia de tabacos, en esa orden se decidió que Martín Xavier de Echeverría fuese repuesto en su cargo: «La actual situación de la Factoría, la decadencia del importante ramo del tabaco, y la necesidad de impedir su ruina, exigen providencias eficaces y oportunas del intento. En este supuesto y atendiendo el Rey al conocimiento e inteligencia que concurren en don Martín Xavier de Echeverría y en don Juan de Mecolaeta para contribuir al restablecimiento del ramo del tabaco ha resuelto que desde luego se les reintegren en sus empleos con los sueldos que gozaban, cesando los que sirven interinamente y entendiéndose esto sin perjuicio de lo que resulte de la causa de la quiebra de don Ignacio de Loynaz» (AGI, Santo Domingo, leg. 2017. Del conde de Gausa a 
SANTIAGO DE LUXÁN MELÉNDEZ Y MONTSERRAT GÁRATE OJANGUREN

LA SEGUNDA FACTORÍA DE LA HABANA ANTES DE LA GUERRA DE LA INDEPENDENCIA

DE LAS TRECE COLONIAS 1760-1779. UNA LECTURA DESDE EL ESTANCO ESPAÑOL

de su gestión por conseguir la mejora de la calidad que, ahora, tan enérgicamente se le demandaba, arrojando dardos envenenados sobre la Secretaría de Indias, de la que no había obtenido la más mínima respuesta a sus sugerencias. La importante cosecha de 1766, primera de la que pudo hacerse cargo Echeverría y la que se esperaba en 1767, demostraba su acierto en la dirección del establecimiento. Los dos grandes instrumentos, sin los que cualquier política de fomento en la Isla no tendría éxito, radicaban en continuar con el reparto de negros, iniciado por Ricla, y en la seguridad de la llegada de los caudales necesarios para la compra de las cosechas y los gastos de mantenimiento de la institución ${ }^{39}$. Otro problema detectado por la nueva administración fue la competencia que los tabacos labrados en la Isla podían hacer a los de Sevilla, de ahí el intento de aumentar los derechos de regalía a los tabacos de los particulares «para contener así el gusto que se iba extendiendo con preferencia a los de Sevilla» ${ }^{40}$. Finalmente, no era menos problemático el privilegio de la molienda en Matanzas por la contrata que ostentaban los condes de Justis y Jibacoa.

Pero de nuevo, a comienzos de 1770, el buen funcionamiento de la Factoría era puesto en entredicho por el marqués de la Corona, uno de los responsables principales de la Renta del tabaco metropolitana que achacaba el mal funcionamiento de la Renta a los recién incorporados responsables de la Factoría en la sociedad habanera:

El Factor, Contador y Tesorero habían formado enlaces por casamientos con las principales familias hacendadas de La Habana, que estos empeños necesariamente los distraía de la incesante vigilancia que pide la comisión a que están destinados y que ocupada la imaginación en los intereses propios y en cuidados de administrar haciendas de azúcares y otras heredadas o plantificadas por ellos mismos se reputaban como vecinos y sujetos a las parcialidades, empeños y obligaciones que son naturales y pide la labranza en que obraba como una de las mayores el tabaco ${ }^{41}$.

\section{Producción y exportación de tabaco desde la isla de CUba EN LA SEgunda MITAD DEL SIGLO XVIII}

Desde fines del siglo xvir se tratará sin éxito de establecer una relación virtuosa entre La Habana como productora de insumos, y la fábrica de Sevilla. Esto no es

\footnotetext{
Juan Ignacio de Urriza (San Ildefonso, 26-VIII-1783). Redactó el nuevo Reglamento por el que se regiría la Factoría, aprobado con su nómina el 15-XII-1783 (Rivero Muñiz, J.: Tabaco. Su historia en Cuba. La Habana, Instituto de Historia, II, 1965, pp. 38-39). Cfr. Luxán, S. y Gárate, M.: «El proceso de instauración..., op. cit.

39. AGS, SSH, leg. 1839: de Echeverría a Múzquiz (La Habana 20-X-1766).

40. AGI, Santo Domingo, leg. 2017, Manifiesto sobre las siembras. Madrid 17-XII-1782.

41. AGI, Santo Domingo, leg. 2017, Manifiesto sobre las siembras. Madrid 17-XII-1782.
} 
SANTIAGO DE LUXÁN MELÉNDEZ Y MONTSERRAT GÁRATE OJANGUREN

LA SEGUNDA FACTORÍA DE LA HABANA ANTES DE LA GUERRA DE LA INDEPENDENCIA

DE LAS TRECE COLONIAS 1760-1779. UNA LECTURA DESDE EL ESTANCO ESPAÑOL

óbice para señalar que otras regiones productoras suministrarán a los establecimientos peninsulares ocasionalmente tabaco (según las épocas, Santo Domingo, Caracas, Paraguay e, incluso, Luisiana). Igualmente se tratará de impulsar una articulación mercantil entre Cuba y el resto del mercado americano, principalmente, en la segunda mitad del xviII. Cuba abasteció en orden de importancia a Cartagena de Indias, Lima, Chile, Panamá, y Nueva España ${ }^{42}$. También hay que tener en cuenta la producción tabaquera en otros territorios centroamericanos que propiciaron unos flujos tabaqueros entre las propias colonias, al margen incluso del tabaco cubano.

El ciclo expansivo de la producción cubana impulsado desde la época de Esquilache se mantendrá hasta 1773, momento en que Múzquiz promoverá un cambio de orientación. Será sin embargo durante el estallido de la independencia de las Trece Colonias, junto a problemas internos de la Factoría, cuando se palie el exceso de oferta diagnosticado desde la metrópoli. Además, si analizamos los datos que disponemos de la evolución de la Factoría más allá de los 70, se puede concluir que tuvo lugar un nuevo ciclo alcista de la producción iniciado al finalizar la citada contienda que tocaría techo en 1789.

Un informe sobre el tabaco entrado en la Factoría, desde su apertura hasta los años finales de su trayectoria, nos proporciona la información del tabaco adquirido en La Habana. Se trata de una valoración oficial de $1803^{43}$. La elección de esta fuente, con todas las limitaciones que pueda llevar consigo, nos permite contar con un cálculo oficial homogéneo de la oferta legal de tabaco. En el período que nos corresponde estudiar en este trabajo, hemos finalizado el cuadro en el que se recoge la información numérica en 1779, que es la fecha de entrada de España en el conflicto anglo-americano y el de la culminación del nuevo marco institucional de la Carrera de Indias (Decreto de Libre Comercio de 1778). Igualmente, en este cuadro, hemos situado las salidas del tabaco cubano con destino a la metrópoli, provenientes de otra información oficial que cubre todo el período histórico comprendido entre la fundación de la Factoría y $1812^{44}$. No obstante y en este último caso, las cifras que se aportan no pueden tomarse como absolutamente

42. Hay que tener presente que Cartagena será una excepción como consumidora de tabaco habanero en el ámbito del Virreinato de Nueva Granada; Panamá, era puerto de trasbordo hacia el Virreinato del Perú; por último en Nueva España se procesó en determinadas épocas tabaco habanero que se remitía también al Perú.

43. Luxán, S. de, Gárate, M. y Rodríguez Gordillo, J. M.: Cuba-Canarias-Sevilla..., 2012, pp. 261-271.

44. NÁter: Integración imperial: el sistema de monopolios de tabaco..., pp. 312-313 («Estado de la entrada anual de tabacos en la factoría general de La Habana tanto en Rama como en polvo, igualmente que sus salidas para la Isla, Europa y América desde su establecimiento en el año de 1761 hasta la fecha», en AGI, Santo Domingo 2023), utiliza un documento semejante, pero con más información, que el publicado por Fernández Pinedo, N.: Comercio exterior y fiscalidad..., 2002. 
SANTIAGO DE LUXÁN MELÉNDEZ Y MONTSERRAT GÁRATE OJANGUREN LA SEGUNDA FACTORÍA DE LA HABANA ANTES DE LA GUERRA DE LA INDEPENDENCIA DE LAS TRECE COLONIAS 1760-1779. UNA LECTURA DESDE EL ESTANCO ESPAÑOL

fiables, ya que no son coincidentes, no solo con el tabaco salido de la fábrica de Sevilla (en donde se computaba tabaco cubano, Brasil y Virginia), sino tampoco con los stocks de la propia fábrica. Sin embargo, en el gráfico que acompaña a estos datos cuantitativos, hemos preferido mantener el recorrido integro de la serie histórica, con el fin de que el lector interesado pueda contextualizar de modo más cabal la etapa que estamos estudiando y los ciclos productivos y exportadores de la Factoría.

CuAdro 2. Tabacos comprados y remitidos por la Factoría de La Habana a la metrópoli (1761-1779) en libras

\begin{tabular}{|l|c|c|}
\hline Años & Entrado en la Factoría & Remitido a la Metrópoli \\
\hline 1761 & 2.515 .100 & 525.736 \\
\hline 1762 & 1.516 .075 & 1.875 \\
\hline 1763 & 948.275 & 2.056 .418 \\
\hline 1764 & 1.232 .175 & 1.208 .883 \\
\hline 1765 & 669.975 & 1.152 .176 \\
\hline 1766 & 3.766 .225 & 1.427 .615 \\
\hline 1767 & 4.174 .100 & 3.228 .751 \\
\hline 1768 & 3.658 .175 & 2.942 .752 \\
\hline 1769 & 2.792 .500 & 3.425 .718 \\
\hline 1770 & 3.074 .650 & 3.309 .078 \\
\hline 1771 & 4.613 .900 & 2.233 .058 \\
\hline 1772 & 5.937 .500 & 3.941 .374 \\
\hline 1773 & 6.748 .375 & 8.822 .143 \\
\hline 1774 & 6.445 .775 & 5.031 .548 \\
\hline 1775 & 4.395 .450 & 3.939 .967 \\
\hline 1776 & 3.425 .100 & 2.554 .018 \\
\hline 1777 & 4.028 .475 & 2.708 .589 \\
\hline 1778 & 3.726 .500 & 1.467 .584 \\
\hline 1779 & 2.009 .900 & 775.325 \\
\hline & & \\
\hline
\end{tabular}

Fuente: AGI. Ultramar 235 y Fernández Pinedo (2002). 
SANTIAGO DE LUXÁN MELÉNDEZ Y MONTSERRAT GÁRATE OJANGUREN

LA SEGUNDA FACTORÍA DE LA HABANA ANTES DE LA GUERRA DE LA INDEPENDENCIA

DE LAS TRECE COLONIAS 1760-1779. UNA LECTURA DESDE EL ESTANCO ESPAÑOL

Gráfico 1. Tabaco entrado en la Factoría de La Habana en libras. 1761-1803

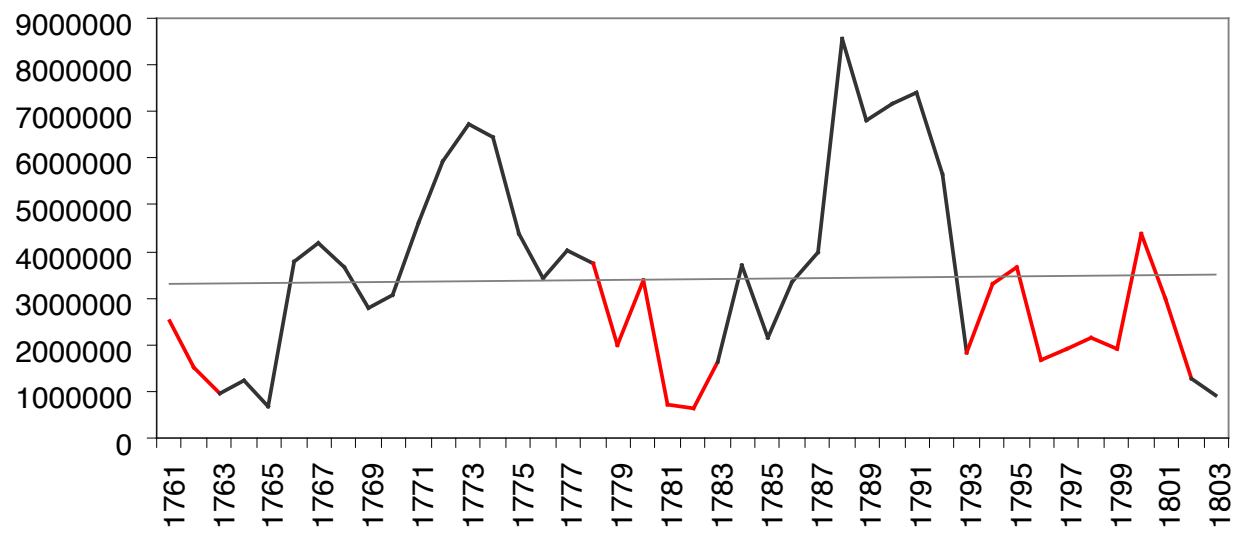

Fuente: AGI. Ultramar 235.

NB: Con objeto de poder valorar la importancia de los conflictos bélicos, que a nuestro entender condicionan de modo notable el tráfico de tabaco, pero no tanto las disponibilidades de la oferta de la Isla, hemos representado en rojo los períodos de guerra ${ }^{45}$.

Para el período comprendido entre 1764-1773, disponemos además de un Informe pormenorizado sobre la cosecha de la Isla del Contador Juan de Mecolaeta ${ }^{46}$, que nos proporciona unas cifras muy superiores a las entradas en la Factoría anotadas en el documento de 1803. La diferencia entre ambas informaciones oficiales puede significar el margen entre el control inicial de las cosechas por parte del establecimiento tabaquero y lo realmente entrado en sus almacenes y, por tanto, el tabaco perdido por la ineficiencia de sus ministros o, simplemente, el disponible para el contrabando. En algunos años la diferencia es muy notable (1764: $31 \%$; $1772: 22 \%$ ), pero, en términos medios, representa una diferencia del $15 \%$.

Del Informe de Juan de Mecolaeta (26-III-1774) se desprende que, en diez años de funcionamiento de la factoría (1764-1773), se habría alcanzado una

45. Luxán Meléndez, S. y Gárate, M.: «La influencia de los conflictos bélicos imperiales en la definición del mercado tabaquero español durante el siglo xviII», en GonZÁlez Enciso, A. (ed.): Un Estado militar. España 1650-1820. Madrid, Actas, 2012, pp. 291-316.

46. AGI, Ultramar, leg. 233. Contador de la Factoría por nombramiento de Juan de Prado desde el 18-II-1761. Fue nombrado administrador en 31-I-1788 en sustitución de Martín de Echeverría, ocupó el cargo hasta su fallecimiento en 1802 (AGI, Ultramar, leg. 234). El 15-XI-1789 presentó una Instrucción para el mejor gobierno y dirección que deben observar los labradores de tabaco de la Jurisdicción de La Habana en el modo de sembrar y beneficiar los que cosechen y entreguen a la Real Factoría de este ramo, asi en la clase de verdines, como en la de secos en Rivero MuÑIZ, op. cit., t. II, 1965, pp. 75-86. 
SANTIAGO DE LUXÁN MELÉNDEZ Y MONTSERRAT GÁRATE OJANGUREN

LA SEGUNDA FACTORÍA DE LA HABANA ANTES DE LA GUERRA DE LA INDEPENDENCIA

DE LAS TRECE COLONIAS 1760-1779. UNA LECTURA DESDE EL ESTANCO ESPAÑOL

media anual de compra de 4.300 .000 libras, con un valor aproximado de 700.000 pesos anuales ${ }^{47}$.

CuAdro 3. Diferencia entre las cosechas y el tabaco entrado en la Factoría (1764-1773) en libras

\begin{tabular}{|c|c|c|c|}
\hline Años & Cosecha & Factoría & Diferencia \\
\hline 1764 & 1.789 .932 & 1.232 .175 & 557.757 \\
\hline 1765 & 753.593 & 669.975 & 83.618 \\
\hline 1766 & 4.279 .515 & 3.766 .225 & 513.290 \\
\hline 1767 & 4.749 .405 & 4.174 .100 & 575.305 \\
\hline 1768 & 4.381 .660 & 3.658 .175 & 723.485 \\
\hline 1769 & 3.310 .958 & 2.792 .500 & 518.458 \\
\hline 1770 & 3.991 .228 & 3.074 .650 & 916.578 \\
\hline 1771 & 5.269 .158 & 4.613 .900 & 655.258 \\
\hline 1772 & 7.105 .354 & 5.937 .500 & 1.167 .854 \\
\hline 1773 & 7.394 .744 & 6.748 .375 & 646.369 \\
\hline Totales & 43.025 .547 & 36.667 .575 & 6.357 .972 \\
\hline
\end{tabular}

Fuente: AGI, Ultramar 235 y Cuba 1219.

El sustituto de Bucareli fue Felipe de Fondesviela y Ondeano marqués de la Torre (1771-1777), hombre con experiencia en las Indias, que llegaba al cargo procedente de la Capitanía de Caracas; le tocó proceder a la reorganización de la Factoría del tabaco, tras las llamadas de alarma de la Fábrica de Sevilla, con el objetivo de frenar su laboreo y aumentar la calidad del producto. Este gobernador impulsaría, por ejemplo, el cultivo de la famosa hoja de Vuelta abajo de Pinar del Río. El marqués dio un giro de $180^{\circ}$ a la política tabaquera, ordenando que se fuera reduciendo y extinguiendo su labranza en los partidos inmediatos a La Habana «donde pudiese el labrador destinar la tierra a otros cultivos con menos quebranto y a prohibir que en las demás se fuera aumentando» ${ }^{48}$. Durante su mandato las

47. AGI, Papeles de Cuba, leg. 1219.

48. Pezuela, Historia de Cuba..., t. III, 1878, p. 105. La imagen que nos ha llegado de él es la de uno de los más profundos conocedores de la economía tabaquera, que supo no convertir la superintendencia del tabaco en una carga. Estuvo al día de la contabilidad, recorrió los partidos, realizó 
SANTIAGO DE LUXÁN MELÉNDEZ Y MONTSERRAT GÁRATE OJANGUREN LA SEGUNDA FACTORÍA DE LA HABANA ANTES DE LA GUERRA DE LA INDEPENDENCIA DE LAS TRECE COLONIAS 1760-1779. UNA LECTURA DESDE EL ESTANCO ESPAÑOL

siembras de tabacos tuvieron un aumento considerable y se le advirtió del exceso de tabaco que había en Sevilla con más de 18 millones de libras sobrantes y que era menester cercenar las siembras y los envíos. Se decidió extinguir solamente las siembras de algunos partidos cercanos a La Habana y prohibir el aumento de siembras en el resto. El aumento de los cultivos llevó a la Factoría a tener problemas financieros para poder pagar las cosechas. Se consiguió incrementar por cuatro años en 100.000 pesos el situado de México. La falta de pagos por parte de otras regiones de América hizo mayores las dificultades financieras de la Factoría. Poco después de su ingreso al gobierno se rebajaron los fletes de 5rs/@ a 4,5 y consiguió disminuirlos aún más hasta llegar a 2,5; además, se suprimió el arancel que se cobraba al tabaco que se traía de las factorías subalternas. Ante las protestas de Sevilla en 1774 por la falta de calidad de las remesas, cuya explicación se buscaba en las salidas clandestinas del de mejor calidad, el marqués de la Torre hizo circular un bando para restringir las futuras siembras de tabaco. Las protestas principales ante esta medida vinieron de los cultivadores de Santiago de Cuba que veían en el tabaco su principal recurso económico. A los cultivadores de Santiago de Cuba se les llegó a deber en 1775 las dos cosechas anteriores. La mayor parte del tabaco exportado a España procedía, sin embargo, de La Habana, Guane y Matanzas, que era donde más abusos parecían cometerse al mezclar las malas con las buenas calidades de rama. La Real Orden de 7 de abril de 1776 planteaba la necesidad de que la cosecha de tabacos no excediese los 3.000 .000 de libras $^{49}$.

El informe de Mecolaeta anteriormente citado estuvo motivado por una Real Orden de 22 de diciembre de 1773, comunicada por Arriaga al capitán general de Cuba marqués de la Torre, en respuesta al testimonio enviado de la Junta de la Factoría de 2 de septiembre de 1774. En aquel se manifestaba el endeudamiento («los empeños») y la necesidad, por tanto, de pedir prestado al intendente de Marina 150.000 pesos y nuevos auxilios -el aumento de las consignaciones- por el incremento de las $\operatorname{cosechas}^{50}$. Es de señalar que en este documento se pone de manifiesto el cambio de la política de Múzquiz, que antes mencionábamos, con

un estudio concienzudo del ramo, modernizó las instalaciones de la Factoría y proyectó un nuevo edificio al que se dio comienzo el 28-III-1773. De su actuación, que sirvió para consolidar la imagen institucional del Capitán General con el inicio de la construcción del Palacio actual de Capitanía y otras obras públicas (1776), nos dejó un largo informe: Apuntes sobre las principales provisiones y operaciones durante mi mando de la Isla de Cuba desde el día 18 de noviembre de 1771 hasta el de la fecha en que lo entregado a mi sucesor el Sr. D. Diego José Navarro (La Habana 11 de junio de 1777. González Ripoll, M. ${ }^{a}$ D.: Cuba, la isla de los ensayos. Cultura y sociedad (1790-1815). Madrid, CSIC, 1999. El documento que utilizó Pezuela se encuentra en Del Monte Papers, caja 4 en la Biblioteca del Congreso de Washington.

49. Rivero MuÑIZ, op. cit., 1965, t. II, pp. 23-24.

50. AGI, Cuba, leg. 1219: Denegación de aumento de consignaciones y siembras. Informe de la Factoría de tabacos de La Habana a Julián Arriaga. 
SANTIAGO DE LUXÁN MELÉNDEZ Y MONTSERRAT GÁRATE OJANGUREN

LA SEGUNDA FACTORÍA DE LA HABANA ANTES DE LA GUERRA DE LA INDEPENDENCIA

DE LAS TRECE COLONIAS 1760-1779. UNA LECTURA DESDE EL ESTANCO ESPAÑOL

relación a la Factoría de La Habana. Se pasó del fomento y expansión del cultivo y la producción iniciado por Esquilache, a una etapa de reducción de compras por parte de la Factoría. Sevilla acumulaba unos stocks tan elevados que pronto saltaron todas las alarmas ${ }^{51}$ :

La calidad de los tabacos en polvo y hoja que se remitían iba de mal en peor, su abundancia en las Fábricas daba temores, hasta contemplar necesario el restringir la siembra en la Isla contra los principios adoptados en 1760 y contra los intereses esenciales de la Renta ${ }^{52}$.

Para explicar este aumento general, anterior al conflicto anglo-americano, se han apuntado, como factores principales: a) la llegada más puntual y en mayor cantidad de los situados de Nueva España; b) una mayor disponibilidad de esclavos, situación que se atribuyó, en sus inicios, a la exitosa gestión del conde de Ricla; c) el aumento de la inmigración canaria y, finalmente, d) la bonanza climatológica. En lo concerniente a la utilización de la mano de obra esclava, en la evolución general de su entrada en la isla, durante la etapa 1763-1774, tuvo lugar un descenso aparente de este tráfico, circunstancia explicada por varios motivos: la intensidad de las importaciones durante el período anterior de dominación inglesa ${ }^{53}$; la menor vinculación entre la producción tabaquera y la utilización de mano de obra forzada ${ }^{54}$; o, sencillamente, porque la entrada clandestina de esclavos sería notable ${ }^{55}$. Con relación a una climatología favorable, no parece tampoco que sea un factor determinante, al menos durante el gobierno de Ricla, en que la meteorología fue adversa. Tampoco, por último, creemos que sea claro el componente de la regularidad de los situados. A tenor de las quejas expresadas por los responsables de la Renta, la discontinuidad y la falta de puntualidad de las consignaciones dificultarán, en grado sumo, el funcionamiento de la Factoría.

51. Torres, R.: «La política económica de la Renta del tabaco...», 2008, p. 299. Este autor señala que la cantidad de tabaco en los almacenes de la fábrica de Sevilla ascendía a 22.000.000 libras. De nuevo nos encontramos con una cantidad que resulta difícil de aceptar a la vista de las entradas en la fábrica de Sevilla y los consumos en la metrópoli.

52. AGI, Santo Domingo, leg. 2017, Manifiesto sobre las siembras, Madrid 17-XII-1782. En representaciones privadas a la Corona de 2-VIII-1774 y de 10-II-1775 se llegó a plantear el comercio general libre de tabacos.

53. Santamaría García, A. y García Álvarez, A.: Economía y colonial. La economía cubana y la relación con España, 1765-1902. Madrid, Consejo Superior de Investigaciones Científicas, Instituto de Historia, Departamento de Historia de América, 2004, p. 78. Después la trata se recuperaría, especialmente como consecuencia de la revolución de Haití.

54. Santamaría García, A. y García Álvarez, A.: op. cit. p. 76, señalan que durante la primera mitad del siglo xix las jurisdicciones donde predominaron las estancias, sitios de labor, vegas de tabaco $\mathrm{y}$, sobre todo, haciendas ganaderas, fueron predominantemente blancas.

55. Moreno Fraginals, M.: El Ingenio. Complejo económico social cubano del azúcar. Barcelona, Crítica, 2001, p. 38. 
SANTIAGO DE LUXÁN MELÉNDEZ Y MONTSERRAT GÁRATE OJANGUREN LA SEGUNDA FACTORÍA DE LA HABANA ANTES DE LA GUERRA DE LA INDEPENDENCIA DE LAS TRECE COLONIAS 1760-1779. UNA LECTURA DESDE EL ESTANCO ESPAÑOL

La información para este período también nos permite conocer la evolución geográfica de los cultivos de tabaco y, por consiguiente, poder apreciar el peso del tabaco de Tierra adentro en el conjunto de la Factoría. La Habana y Matanzas, excepto en el ejercicio de 1769, en que los Partidos de Tierra adentro se ponen ligeramente por encima, cosecharán siempre más tabaco (Cfr. Gráfico 2).

GRÁfICO 2. Distribución territorial del tabaco 1764-1773

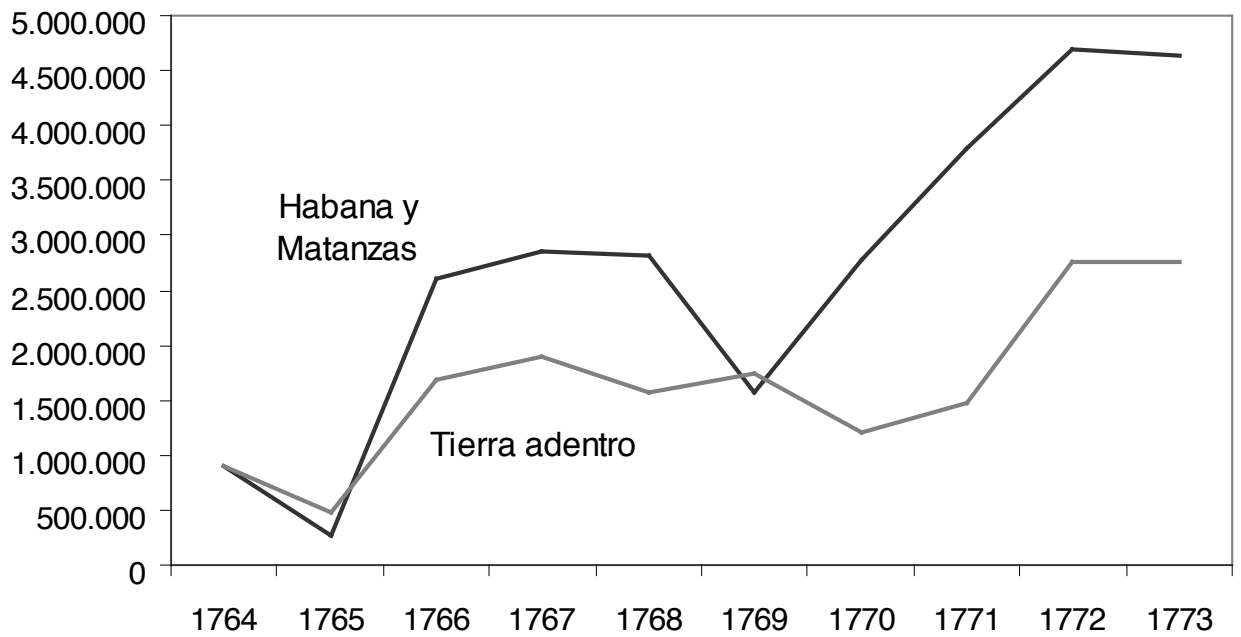

Fuente: AGI, Cuba, leg. 1219.

\section{I. ¿Qué cantidad de tabaco se embarcó desde La Habana a la metrópoli?}

Para responder a este interrogante disponemos de las cifras de tabaco embarcadas con destino a la metrópoli, recopiladas unos años después que el informe anterior, por la propia administración. Es el momento en que Arango Parreño eludió el nombramiento de asesor del monopolio y en el que los intereses azucareros-que el mismo representaba- presionaban para que la Factoría se extinguiese ${ }^{56}$.

56. AGI, Ultramar, leg. 235: carta por la vía reservada del Superintendente de tabacos de La Habana a Miguel Cayetano Soler de 8-I-1806. Arango había sido nombrado asesor en junio de 1804. La información más sustancial se recopila con motivo del debate sobre el desestanco en las Cortes de Cádiz. En este sentido es esclarecedor el informe presentado por José González Montoya formado a petición de Canga Argüelles (9-I-1812): AGI, Santo Domingo, leg. 2002, «Examen y arreglo de la Factoría de Tabacos (sin estanco) en la Isla de Cuba por el Superintendente de La Habana D. JPH González Montoya de orden del Gobierno». Habana en la Imprenta de don Esteban José Boloña, 1814. 
SANTIAGO DE LUXÁN MELÉNDEZ Y MONTSERRAT GÁRATE OJANGUREN

LA SEGUNDA FACTORÍA DE LA HABANA ANTES DE LA GUERRA DE LA INDEPENDENCIA

DE LAS TRECE COLONIAS 1760-1779. UNA LECTURA DESDE EL ESTANCO ESPAÑOL

Como hemos señalado antes, solamente nos vamos a referir a la etapa inicial de los envíos, que termina con la Guerra de la Independencia de las Trece Colonias e, igualmente, hemos representado en rojo los conflictos bélicos.

Gráfico 3. Envíos de Tabaco de La Habana a España (1761-1812) en libras

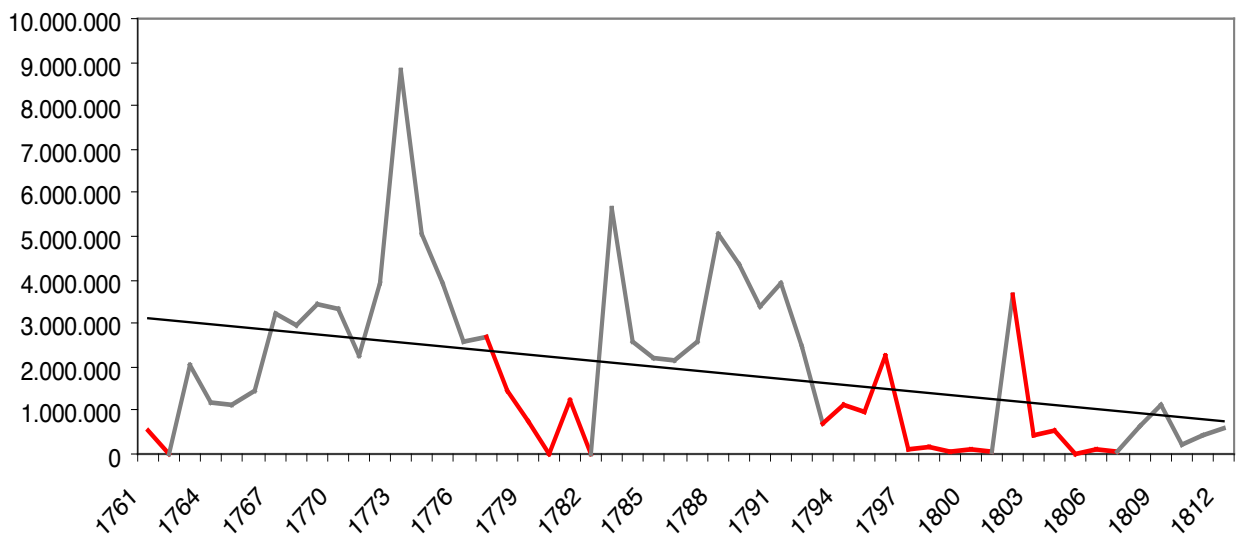

Fuente: Náter (2000) y Fernández Pinedo (2002), elaboración propia.

Debemos mencionar que el clásico estudio de García Baquero, Cádiz y el Atlántico 1717-1778 (1988), nos ofrece una información exhaustiva de los navíos de la Carrera de Indias y su carga, a través de los registros de la Casa de Contratación de Cádiz. Con relación al tabaco, los datos de la aduana de Cádiz difieren notablemente de los libros de cargo y data de la Fábrica de Sevilla. La serie histórica que puede elaborarse siguiendo los apéndices de la carga de los navíos de esta obra, discrepa igualmente, de modo sustancial, de los Informes de la Factoría que hemos utilizado. Los tabacos extraídos de La Habana con destino a Cádiz representan más del doble en la serie de Náter y Fernández Pinedo, que en la elaborada sobre los datos de García Baquero, entre 1763-1777. Esta diferencia hace poco creíbles los valores del historiador de Cádiz y el Atlántico, y reafirman la lectura realizada en su día por Rodríguez Gordillo ${ }^{57}$.

Seguramente existió un alto grado de correlación entre el tabaco recogido por la Factoría y el embarcado con dirección a Cádiz, circunstancia que no se aprecia en la fuente aportada por Náter y Fernández Pinedo. Este tráfico solamente se

57. Rodríguez Gordillo, J. M.: «El abastecimiento de tabacos en el marco del estanco español en el siglo xviII: reflexiones previas para su estudio», en GONZÁLEZ EnCISO y TorRes SánCHEZ (eds.), Tabaco y economía en el siglo XVIII. Pamplona, Eunsa, 1999, pp. 239-70. 
SANTIAGO DE LUXÁN MELÉNDEZ Y MONTSERRAT GÁRATE OJANGUREN LA SEGUNDA FACTORÍA DE LA HABANA ANTES DE LA GUERRA DE LA INDEPENDENCIA DE LAS TRECE COLONIAS 1760-1779. UNA LECTURA DESDE EL ESTANCO ESPAÑOL

rompe como consecuencia de los enfrentamientos militares en los que incluso llega a interrumpirse.

Por último, debemos añadir que hay un cierto desajuste entre los tráficos internos (el acarreo del tabaco desde los partidos a la Factoría) y los flujos externos (embarques a la metrópoli). Efectivamente, durante los ejercicios de 1769-1770, 1773, 1781, 1783, 1796 y 1802 (como puede apreciarse en el Gráfico 4), las salidas hacia Cádiz están por encima de las entradas en la Factoría. Las dos circunstancias iniciales tienen que ver con la evolución interna de la producción, pero los cuatro períodos siguientes se relacionan directamente con los conflictos bélicos.

Gráfico 4. Tabaco enviado en la Factoría y remitido a la metrópoli en libras (1761-1803)

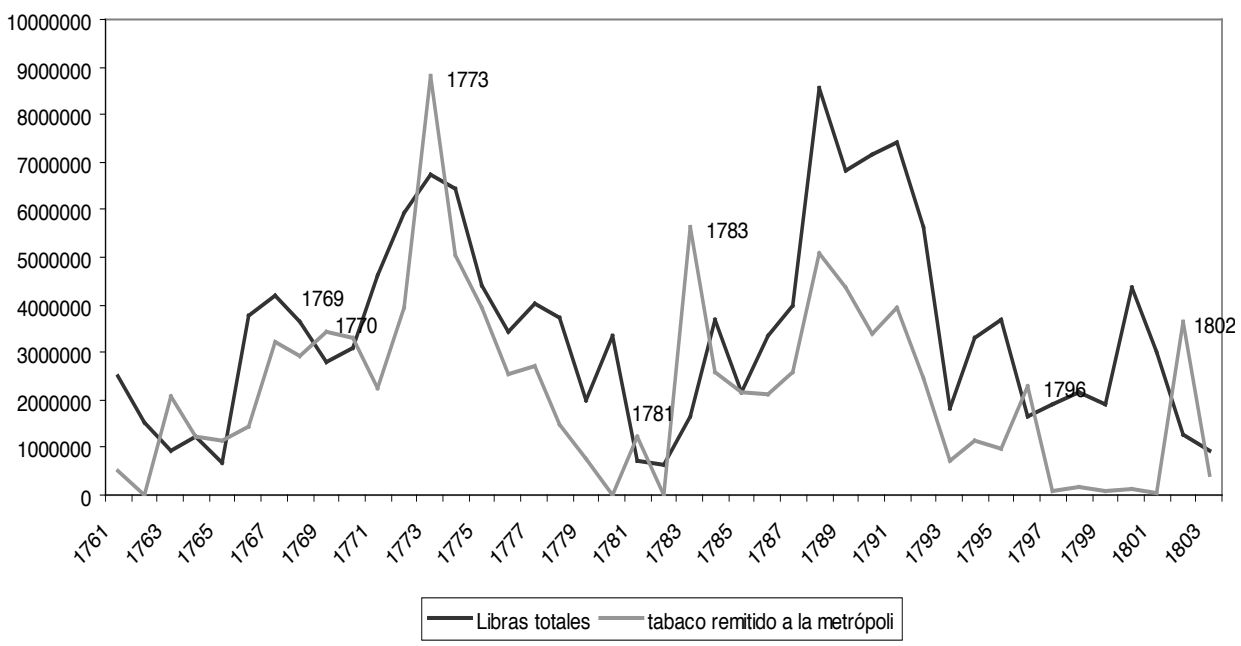

Fuente: para las entradas en la Factoría (AGI, Ultramar, leg. 235) y para las remesas a la metrópoli (Fernández Pinedo, 2002).

4.2. ¿Podemos conocer el volumen total de tabaco producido en la Isla durante la Segunda Factoría?

Disponemos, al respecto, de la estimación realizada por Santamaría García sobre fuentes indirectas ${ }^{58}$, en la que pretende valorar las exportaciones totales de

58. Santamaría García, A.: «Reformas coloniales, economía y especialización productiva en Puerto Rico y Cuba, 1760-1850», Revista de Indias, 65:235, 2005, pp. 720. La información procede de Humboldt, de la Sagra, de la Pezuela, Pérez de la Riva, Rivero Muñiz, Goizueta-Mimo, Moreno Fraginals y el Instituto de Historia de Cuba. 
SANTIAGO DE LUXÁN MELÉNDEZ Y MONTSERRAT GÁRATE OJANGUREN LA SEGUNDA FACTORÍA DE LA HABANA ANTES DE LA GUERRA DE LA INDEPENDENCIA DE LAS TRECE COLONIAS 1760-1779. UNA LECTURA DESDE EL ESTANCO ESPAÑOL

tabaco que, a su vez, utiliza como indicador de la producción. Desde nuestro punto de vista, su mayor interés reside en la demostración palpable de que después de la Guerra de Independencia de Estados Unidos, el mercado español dejó de ser el consumidor principal del tabaco cubano.

Si aceptamos la propuesta de este historiador podemos estructurar la historia de la producción cubana durante la Segunda factoría en tres grandes períodos: 1760-1784, 1785-1799 y 1800-1819, con sus correspondientes fases de alza y baja seriamente condicionadas por los conflictos bélicos en los que se vio envuelta la Monarquía española. La curva en la que se recogen los datos de exportación a España de Fernández de Pinedo nos muestra una evolución muy diferente a partir de 1784 y durante el ciclo bélico anglo-español de 1796-1808. La información proporcionada por Santamaría ofrece un amplio margen que puede ser explicado por las exportaciones desde Cuba al resto de América y por la intervención de los agentes que actúan fuera del estanco, especialmente en las dos últimas décadas del siglo.

La producción tabaquera de la Isla de Cuba aumentaría, como también lo hicieron, aunque con mayor intensidad las zafras azucareras, hasta el quinquenio 1810-1814, en contraste con los envíos a España, que se contraen de modo espectacular. Esta situación favorecerá, aún más, el contrabando y la presencia del tabaco de Brasil y de Virginia en el mercado metropolitano.

Gráfico 5. Exportaciones de tabaco de Cuba en libras (1760-1819)

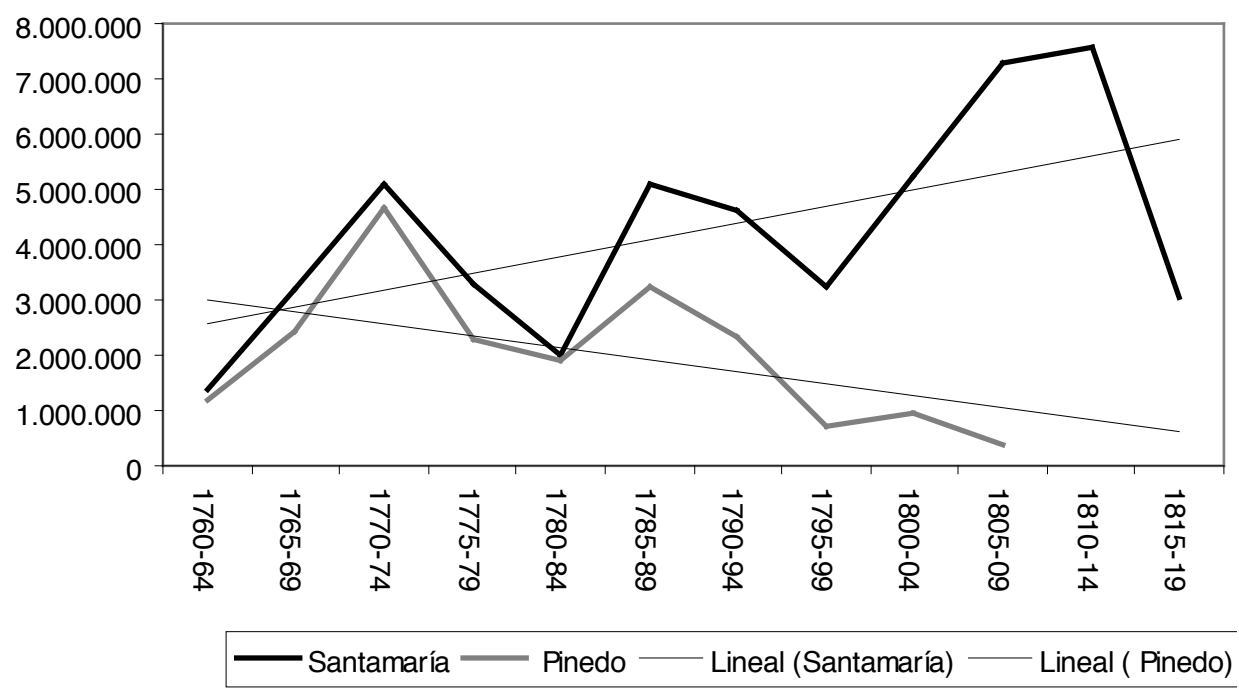

Fuente: Santamaría García (p. 720), Náter (pp. 311-312) y Fernández Pinedo (pp. 124-125). 
SANTIAGO DE LUXÁN MELÉNDEZ Y MONTSERRAT GÁRATE OJANGUREN

LA SEGUNDA FACTORÍA DE LA HABANA ANTES DE LA GUERRA DE LA INDEPENDENCIA

DE LAS TRECE COLONIAS 1760-1779. UNA LECTURA DESDE EL ESTANCO ESPAÑOL

Otro aspecto que debemos tener en cuenta, entre las magnitudes que son necesario ponderar, para entender la evolución tabaquera y azucarera, es el tráfico de esclavos. Como hemos señalado, la liberalización de su comercio, inclinará definitivamente el peso de la economía sobre el sector de los ingenios azucareros.

Cuadro 4. Producción de azúcar y tabaco 1760-1819 (medias anuales)

\begin{tabular}{|c|c|c|c|c|}
\hline Quinquenios & Azúcar en libs. & Índice & Tabaco en libs. & Índice \\
\hline $1760-64$ & 11.521 .739 & 100 & 1.390 .720 & 100 \\
\hline $1765-69$ & 13.195 .652 & 114 & 3.173 .894 & 228 \\
\hline $1770-74$ & 15.717 .391 & 138 & 5.108 .665 & 367 \\
\hline $1775-79$ & 18.326 .086 & 159 & 3.281 .230 & 235 \\
\hline $1780-84$ & 16.630 .434 & 119 & 1.978 .249 & 142 \\
\hline $1785-89$ & 24.173913 & 209 & 5.108 .665 & 367 \\
\hline $1790-94$ & 36.152 .173 & 313 & 4.606 .760 & 331 \\
\hline $1795-99$ & 52.391 .304 & 454 & 3.259 .500 & 234 \\
\hline $1800-04$ & 75.934 .782 & 659 & 5.239 .099 & 376 \\
\hline $1805-09$ & 84.695 .652 & 735 & 7.304 .304 & 525 \\
\hline $1810-14$ & 77.021 .739 & 668 & 7.586 .911 & 545 \\
\hline $1815-19$ & 101.239 .130 & 878 & 3.063 .930 & 220 \\
\hline
\end{tabular}

Fuente: Santamaría García (p. 720). Elaboración propia.

La lectura comparada de la evolución de la producción de azúcar y tabaco (Cf. Cuadro 4 y gráfico 7), los dos renglones básicos, junto al café, de la segunda mitad del siglo xvinI, nos permite considerar que, en términos relativos, el tabaco recupera de modo notable posiciones en los tres primeros lustros de la factoría, lo que parece confirmar el éxito de esta andadura. Efectivamente, de representar el 10,8\% de la exportación conjunta de azúcar y tabaco, llega a alcanzar más de la cuarta parte de las salidas en el período de 1770-1774, momento en que se disparan las alarmas sobre el exceso de oferta. 
SANTIAGO DE LUXÁN MELÉNDEZ Y MONTSERRAT GÁRATE OJANGUREN

LA SEGUNDA FACTORÍA DE LA HABANA ANTES DE LA GUERRA DE LA INDEPENDENCIA

DE LAS TRECE COLONIAS 1760-1779. UNA LECTURA DESDE EL ESTANCO ESPAÑOL

Inmediatamente después de la guerra de Estados Unidos, mientras rige los destinos de la isla Ezpeleta (1785-1790) ${ }^{59}$, asistimos a un nuevo repunte del tabaco, que se coloca ahora entre el $17-18 \%$ de las exportaciones conjuntas. Circunstancia que puede deberse, en parte, a la acumulación de stocks durante el conflicto bélico. A partir de ese momento, la pérdida de peso es imparable. Son los años de liberalización máxima de la trata y del azúcar, y de la mayor creación de ingenios azucareros a costa de las vegas tabaqueras y, sobre todo, de la nueva posición de Cuba en el mercado mundial del azúcar, tras la revolución de Haití. Desde 17951799, hasta la clausura del estanco, aunque los tres primeros quinquenios del xix supongan un importante auge de la producción tabaquera, el porcentaje medio anual apenas superará el 6\%, siendo especialmente fuerte la caída en el lustro último de la factoría.

Debemos mencionar que en la etapa posterior a la Guerra de la Independencia de las Trece Colonias los gobernadores-capitanes generales perdieron protagonismo en el gobierno del tabaco. Efectivamente, el intendente se hizo cargo, a partir de 1783, de la superintendencia del tabaco, pasando el gobernador a un segundo plano. Ignacio Urriza ${ }^{60}$, José Pablo Valiente y Luis de Viguri fueron los principales intendentes de este período que significaba el final del control del tabaco por parte de la hacienda real: «A instancias de los mismos capitanes generales que repugnaban entender en materias tan extrañas al gobierno militar y aún al político, había sido declarada anexa desde el 26 de agosto [1783] al Intendente, al jefe de las otras rentas, la superintendencia de aquel valioso ramo que, en lugar de progresar, mermó y retrocedió desde que lo dirigieron manos más facultativas» ${ }^{61}$. Esta afirmación de Pezuela concuerda con el cambio hacia la economía azucarera que vivió la Isla y en la que algún capitán general (Luis de las Casas) se vio implicado ${ }^{62}$.

59. Amores, J. B.: Cuba en la época de Ezpeleta (1785-1790). Pamplona, Eunsa, 2000.

60. Al crearse la intendencia de Cuba, a instancias de Ricla, en 1764, se dictaron para ella unas ordenanzas -a la que se introdujeron cambios en 1765 y 1767-, determinándose que el intendente de La Habana lo era de «ejército y hacienda», para darle una importante intervención en temas económicos, pero careciendo de competencias políticas. Tales ordenanzas rigieron hasta su reemplazo, en 1786, por las aplicadas en Nueva España. $C f r$. Amores, J. B.: «Juan Ignacio de Urriza y la intendencia de La Habana (1776-1787)», en: Escobedo, R.; Zaballa, A. de y Álvarez-Gila, O. (eds.): Euskal Herria y el Nuevo Mundo. La contribución de los vascos a la formación de las Américas. Vitoria, Universidad del País Vasco, 1996, pp. 227-247; del mismo autor: «La Intendencia de Ejército y Hacienda en Cuba: origen y primera organización (1765-1775)», en XI Congreso del Instituto Internacional de Historia del Derecho Indiano. Actas y Estudios, I, Buenos Aires, Instituto de Investigaciones de Historia del Derecho, 1996, pp. 9-30; igualmente, del mismo autor: «El intendente de La Habana Juan Ignacio de Urriza y la política imperial de Carlos III (1776-1787)», en González Enciso, A. (ed.): Navarros en la Monarquía española en el siglo XVIII. Pamplona, Eunsa, 2007, pp. 185-214.

61. Pezuela, Historia de Cuba..., t. III, 1878, p. 196.

62. GonZÁlez-Ripoll, op. cit. 
SANTIAGO DE LUXÁN MELÉNDEZ Y MONTSERRAT GÁRATE OJANGUREN

LA SEGUNDA FACTORÍA DE LA HABANA ANTES DE LA GUERRA DE LA INDEPENDENCIA

DE LAS TRECE COLONIAS 1760-1779. UNA LECTURA DESDE EL ESTANCO ESPAÑOL

GRÁfico 6. Índices de la producción azucarera y tabaquera (1760-1819) según Santamaría (2005)

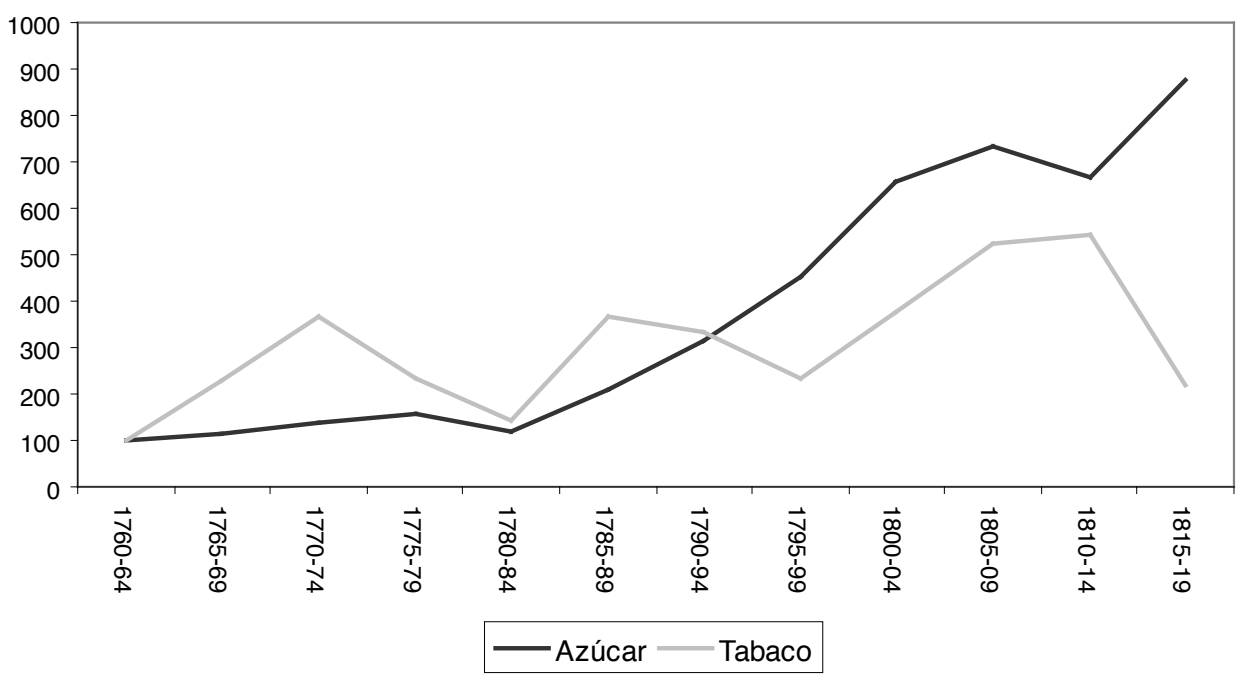

Fuente: Santamaría García, p. 720.

\section{Reflexiones FinAles}

La producción del tabaco cubano se incrementó de modo muy notable durante la segunda mitad del xviri. La comparación, por ejemplo, con el período de la Compañía de La Habana, en el que el trasiego anual medio legal hacia la metrópoli se situó en torno a los dos millones de libras, es claramente favorable a la segunda factoría, que para toda su existencia alcanzará más del doble de la exportación de la Compañía. Esta diferencia puede ser explicada, en parte, por el carácter de «empresa imperial» que hay que darle a la segunda Factoría, que extendió sus mercados al resto de las Indias, puesto que el consumo de tabaco cubano en la metrópoli fue incapaz de crecer, en la modalidad de polvo.

El funcionamiento de la Factoría se basó en un doble sistema exclusivista. De un lado, el aplicado a la producción de tabaco. La Factoría fue algo más que una institución que monopolizaba la compra del tabaco, dado que sometió al cultivo, recolección y manipulación del producto en los molinos, a una estrecha regulación, no dejando prácticamente lugar a la actividad privada. De otro, la fórmula de puerto único de salida de la que gozó La Habana, que obstaculizó la salida del producto desde los puertos del Oriente. Desde esta perspectiva Santiago de Cuba fracasó en el papel de alternativa al tabaco habanero en los mercados metropolitanos. 
SANTIAGO DE LUXÁN MELÉNDEZ Y MONTSERRAT GÁRATE OJANGUREN LA SEGUNDA FACTORÍA DE LA HABANA ANTES DE LA GUERRA DE LA INDEPENDENCIA DE LAS TRECE COLONIAS 1760-1779. UNA LECTURA DESDE EL ESTANCO ESPAÑOL

La segunda Factoría pretendía mantener asegurado el abastecimiento de las fábricas reales, poniendo un énfasis especial en la calidad del producto. Desde esta perspectiva, se prestó atención a los informes de los responsables de la Fábrica de Sevilla, pero también a los elaborados por los ministros cubanos. No obstante, desde el principio, parece vislumbrarse un diálogo de sordos, o una falta de entendimiento entre ambos polos.

El establecimiento de la Segunda Factoría intentó realizarse con el mayor consenso posible de los agricultores y hacendados cubanos, que nunca pusieron en tela de juicio la existencia de la factoría que, en todo caso, fue considerada como moneda de cambio en la consecución de las reformas comerciales de 1765.

La política impulsada con la creación de la Factoría de la Habana en 1760 chocó, sin embargo, con la enorme dificultad encontrada por tabaco cubano para abastecer en exclusiva el mercado español y con la escasa capacidad del mercado legal americano. Un fuerte desequilibrio, por lo tanto, entre la producción y la capacidad de los mercados estancados, tanto del Imperio español, como de la metrópoli, para absorberla.

Las directrices de funcionamiento encaminadas a la consolidación del nuevo sistema, giraron en torno a la organización; a la selección de sus funcionarios; a la vigilancia imposible de la puntualidad de los situados de la Nueva España; al cuidado atento del proceso de cultivo y elaboración del producto; al control de los molinos; a la seguridad del transporte por mar recurriéndose a los navíos de guerra; a la mayor participación del Oriente; a la aminoración de las catástrofes naturales; así como, a la promoción de los envíos a otras partes de las Indias.

Finalmente, dada la existencia del monopolio cuya importancia para la Hacienda borbónica ha sido reiteradamente recogida por la historiografía, resulta casi imposible pensar en la Cuba del xviII, en otros términos que no sean los de principal abastecedora del estanco. Otra cosa es valorar, si las fórmulas de monopolio, como las que se practicaron antes de 1760, hubiesen podido aportar una mayor rentabilidad para la Hacienda, menos inestabilidad en la financiación y un desarrollo mayor de la economía tabaquera, no solo producción de rama, sino también elaboración de cigarros, como iba a ocurrir en el siglo XIX.

\section{BiBLIOGRAFÍA}

Acuña Ortega, V::«Historia Económica del tabaco en Costa Rica, época colonial», en Anuario de Estudios Sociales Centro Americanos, San José, Instituto de Investigaciones Sociales de la Universidad de Costa Rica, 4, 1978, pp. 278-392.

Amores, J. B.: «Juan Ignacio de Urriza y la intendencia de La Habana (1776-1787)», en: Escobedo, R., Zaballa, A. de y Álvarez-Gila, O. (eds.): Euskal Herria y el Nuevo Mundo. La contribución de los vascos a la formación de las Américas. Vitoria, Universidad del País Vasco, 1996, pp. 227-247. 
SANTIAGO DE LUXÁN MELÉNDEZ Y MONTSERRAT GÁRATE OJANGUREN LA SEGUNDA FACTORÍA DE LA HABANA ANTES DE LA GUERRA DE LA INDEPENDENCIA DE LAS TRECE COLONIAS 1760-1779. UNA LECTURA DESDE EL ESTANCO ESPAÑOL

Amores, J. B.: «La Intendencia de Ejército y Hacienda en Cuba: origen y primera organización (1765-1775)», en XI Congreso del Instituto Internacional de Historia del Derecho Indiano. Actas y Estudios, I, Buenos Aires, Instituto de Investigaciones de Historia del Derecho, 1996, pp. 9-30.

Amores, J. B.: Cuba en la época de Ezpeleta (1785-1790). Pamplona, Eunsa, 2000.

Amores, J. B.: «El intendente de La Habana Juan Ignacio de Urriza y la política imperial de Carlos III (1776-1787)», González Enciso, A. (ed.): Navarros en la Monarquía española en el siglo XVIII. Pamplona, Eunsa, 2007, pp. 185-214.

Arcila Farías, E.: Historia de un Monopolio. El Estanco del Tabaco en Venezuela (17791833). Caracas, Universidad Central de Venezuela, 1977.

Arias Divito, J. C.: «Dificultades para establecer la Renta del Tabaco en Paraguay», Anuario de Estudios Americanos, 33, 1976, pp. 1-17.

Arias Divito, J. C.: «Establecimiento de la Renta de Tabacos y Naipes en el Virreinato del Río de La Plata 1778-1781», Historiografía Rioplatense, 1, 1978, pp. 7-56.

Céspedes del Castillo, G.: «La Renta del tabaco en el virreinato del Perú», Revista Histórica, 21, 1954, pp. 138-163.

CÉspedes, G.: El tabaco en Nueva España. Madrid, Real Academia de la Historia, 1992.

Cooney, J.: «Fraude y burócratas: tabaco y Paraguay 1789-1790», Revista Paraguaya de Sociología, 29:85, 1992, pp. 29-40.

Cooney, J.: «La Dirección General de la Real Renta de Tabacos and the Decline of the Royal Tobacco Monopoly in Paraguay», Colonial Latin American Historical Review, $1: 1,1992$, pp. 101-115.

Dean-Smith, S.: «The Money Plant: The Royal Tobacco Monopoly of New Spain 17651821», en Jacobsen, N. y Pulhe, H. J. (eds.): The Economies of Mexico and Perú during de Late Colonial Period 1760-1810. Berlín, Colloquium Verlag, 1986, pp. 361-387.

Dean-Smith, S.: Bureaucrats, Planters and Workers. The Making of the Tobacco Monopoly in Bourbon Mexico. Austin, University of Texas Press, 1992.

Dean-Smith, S.: «El Estanco del Tabaco en el México Borbónico», en González Enciso, A. y Torres, R. (eds.): Tabaco y economía en el siglo XVIII. Pamplona, Eunsa, 1999, pp. 79-106.

Escobedo, R.: «La expansión geográfica de la Renta del Tabaco», Estudis, 33, 2007, pp. 193-224.

Fallas Barrantes, M.: La Factoría de Tabacos de San José de Costa Rica. San José, Editorial de Costa Rica, 1972.

Fernández de Pinedo, N.: Comercio exterior y fiscalidad: Cuba (1794-1860). Bilbao, Universidad del País Vasco, 2002.

Fisher, J. R.: «El estanco del tabaco en el Perú borbónico», en González Enciso, A. y Torres Sánchez, R. (eds.): Tabaco y Economía en el siglo XVIII. Pamplona, Eunsa, 1999, pp. 31-53. 
SANTIAGO DE LUXÁN MELÉNDEZ Y MONTSERRAT GÁRATE OJANGUREN LA SEGUNDA FACTORÍA DE LA HABANA ANTES DE LA GUERRA DE LA INDEPENDENCIA DE LAS TRECE COLONIAS 1760-1779. UNA LECTURA DESDE EL ESTANCO ESPAÑOL

GÁrate, M. y Luxán, S.: «Tabaco y política económica en Cuba a finales del siglo xvinı», en González Enciso, A. (ed.): Politica económica y gestión de la Renta del Tabaco en el siglo XVIII. Madrid, Fundación Altadis-Ediciones El Umbral, 2008, pp. 341-371.

GÁrate, M. y Luxán, S.: «Cuba y Nueva España: los dos pilares del tabaco español en el siglo XVIII», Ulúa, 14, 2009, pp. 35-74.

Gárate, M. y Luxán, S.: «Ilustración y reformismo económico en América durante el reinado de Carlos III (Tabaco y Hacienda)», en Astigarraga, J.; López Cordón, M. V. y Urkía, J. M. (eds.): Ilustración, Ilustraciones. San Sebastián, Real Sociedad Bascongada de Amigos del País-Sociedad Estatal de Conmemoraciones Culturales, 2009, vol. II, pp. 485-510.

García Baquero, A.: Cádiz y el Atlántico 1717-1778. Cádiz, Diputación provincial de Cádiz, 1988.

García Fernández, M. N.: Comerciando con el enemigo: el tráfico mercantil angloespañol en el siglo XVIII (1700-1765). Madrid, CSIC, 2006.

González, M.: «El estanco colonial del tabaco», Cuadernos colombianos, 8, 1975, pp. 637-707.

GonzÁlez-Ripoll, M. a D. (1999): Cuba, la isla de los ensayos. Cultura y sociedad (17901815). Madrid, CSIC, 1999.

Gray, S. y Wyckoff, V. J.: «The international tobacco trade in the seventeenth century», The Southern Economic Journal, 1940, pp. 1-26.

Gutiérrez Escudero, A.: «Tabaco y algodón en Santo Domingo, 1731-1795», en Sarabia, J. y otros: Entre Puebla de los Angeles y Sevilla. Sevilla, Universidad de SevillaEscuela de Estudios Hispano Americanos, 1987.

Gutiérrez Escudero, A.: «El tabaco en Santo Domingo y su exportación a Sevilla (época colonial)», en Vila, E. y Kuethe, A. (eds.): Relaciones de poder y comercio colonial. Sevilla, Escuela de Estudios Hispano Americanos, 1999, pp. 117-142.

Gutiérrez Escudero, A.: «Tabaco y desarrollo económico en Santo Domingo», Anuario de Estudios Americanos, 58, 2001, pp. 713-736.

Harrison, John P.: The Colombian Tobacco Industry from Governement Monopoly to Free Trade 1778-1870, Disertación Doctoral, Universidad de California, 1951.

Hunnefeldt, Ch.: «Etapa final del monopolio en el Virreinato del Perú: el tabaco de Chapapoyas", en Jacobsen, N. y Pulhe, H. J. (eds.): The Economies of Mexico and Peru during the Late Colonial Period. Berlín, Colloquium Verlag, 1986, pp. 388-417.

Kuethe, A. J.: Cuba 1753-1815. Knoxville, The University of Tennesse Press, 1986.

Laviana Cuetos, M. ${ }^{a}$ L.: «La renta del tabaco en el Guayaquil colonial», Revista Ecuatoriana de Historia Económica, 9, 1994, pp. 13-136.

Lucena Salmoral, M. «Las dificultades de la agricultura comercializable caraqueña a fines del régimen español y la necesidad de una reforma». Quinto Centenario. Revista Complutense de Historia de América, 4, 1982, pp. 15-48.

Luján Muñoz, J.: «El Establecimiento del estanco del Tabaco», Mesoamérica, 41, 2001, pp. 99-136. 
SANTIAGO DE LUXÁN MELÉNDEZ Y MONTSERRAT GÁRATE OJANGUREN LA SEGUNDA FACTORÍA DE LA HABANA ANTES DE LA GUERRA DE LA INDEPENDENCIA DE LAS TRECE COLONIAS 1760-1779. UNA LECTURA DESDE EL ESTANCO ESPAÑOL

Luxán, S.: «La defensa global del Imperio y la creación de los monopolios fiscales del tabaco americanos en la segunda mitad del siglo xviII», en Luxán, S. (ed.), Política $y$ hacienda del tabaco en los Imperios Ibéricos (siglos XVII-XIX). Madrid, Centro de Estudios Políticos y Constitucionales, 2014, pp. 177-229.

Luxán, S. de y Gárate, M.: «El proceso de instauración de la segunda factoría en Cuba (1760-1766), en González Enciso, A. (ed.): Política económica y gestión de la Renta del Tabaco en el siglo XVIII. Madrid, Fundación Altadis-Ediciones El Umbral, 2008, pp. 211-281.

Luxán, S. de y Gárate, M.: «La creación de un Sistema Atlántico del Tabaco (siglos XVII-XVIII). El papel de los monopolios tabaqueros. Una lectura desde la perspectiva española», Anais del Centro de Historia de Além-Mar, XI, 2010, pp. 145-175.

Luxán, S. de, GÁrate, M. y Rodríguez Gordillo, J. M.: Cuba-Canarias-Sevilla. El estanco español del tabaco y las Antillas (1717-1817). Las Palmas de Gran Canaria, Ediciones del Cabildo Insular, 2012.

Lluberes Navarro, A.: «Tabaco y catalanes en Santo Domingo durante el siglo XviII», $E M E, \mathrm{~V}: 28$, Santiago (Rep. Dominicana), 1997, pp. 13-26.

McWaters, D. L: The Royal Tobacco Monopoly in Bourbon Mexico 1764-1810. University of Florida, Tesis doctoral, 1979.

Moreno Fraginals, M.: El Ingenio. Complejo económico social cubano del azúcar. Barcelona, Crítica, 2001.

NARDI, J. B.: Le Tabac brésilien et ses fonctions dans l'ancien système colonial portugais: 1570-1830. Marsella, 1991.

NÁTER VÁzQuez, L.: Integración imperial: el sistema de monopolios de tabaco en el Imperio español. Cuaba y América en el siglo XVIII. Tesis doctoral inédita, Centro de Estudios Históricos El Colegio de México, 2000.

Parcero, M. C.: La pérdida de La Habana y las reformas borbónicas en Cuba, 1760-1773. Ávila, Junta de Castilla y León, 1998.

Pezuela, J. de la: Historia de la Isla de Cuba. Madrid, 1868 y 1878, vols. $2^{\circ}$ y $3^{\circ}$.

Pezuela, J. de la: Diccionario Geográfico Estadistico Histórico de la Isla de Cuba del mismo historiador. Madrid, Imprenta del Banco Industrial y Mercantil, 1863-1867.

Pierson, W. W.: «La Intendencia de Venezuela en el régimen colonial», Boletín de la Academia Nacional de la Historia, tomo XXIV, 95, Caracas, 1941, pp. 259-275.

Price, J. M.: France and the Chesapeake. A History of the French Tobacco Monopoly, 1674-1791, and of Its Relationship to the British and American Tobacco Trades. An Arbor, the University of Michigan Press, 1973.

Priestley, H. I.: José de Gálvez, Visitor-General of New Spain 1765-1771. Berkeley, 1916.

Rico Aldave, J.: La Renta del Tabaco en Costa Rica (1766-1860). Universidad Pública de Navarra, Tesis doctoral inédita, 2008.

Rivera, J. C. y Castro, E. C.: «El Real Estanco del Tabaco en Nueva España», en AmerLINCK, M. y otros: Historia y cultura del tabaco en México. México, Tabamex-Secretaria de Agricultura y Recursos Hidraúlicos, 1988, pp. 105-126.

Rivero MuñIz, J.: Tabaco. Su historia en Cuba. La Habana, Instituto de Historia, 1964-1965. 
SANTIAGO DE LUXÁN MELÉNDEZ Y MONTSERRAT GÁRATE OJANGUREN LA SEGUNDA FACTORÍA DE LA HABANA ANTES DE LA GUERRA DE LA INDEPENDENCIA DE LAS TRECE COLONIAS 1760-1779. UNA LECTURA DESDE EL ESTANCO ESPAÑOL

Rordríguez Gordillo, J. M.: «El abastecimiento de tabacos en el marco del estanco español en el siglo xviII: reflexiones previas para su estudio», en GonzÁlEz EnCIso, A. y Torres Sánchez, R. (eds.), Tabaco y economía en el siglo XViri. Pamplona, Eunsa, 1999.

Rodríguez Gordillo, J. M.: La difusión del tabaco en España. Diez estudios. Sevilla, Universidad de Sevilla-Fundación Altadis, 2002, pp. 137-138.

Rodríguez Gordillo, J. M.: «La influencia del tabaco de Virginia en la configuración del mercado español en la segunda mitad del siglo xviI», en Vila Vilar, E. y Lacueva MuÑOz, J. (coords.): Mirando las dos orillas: intercambios mercantiles, sociales y culturales entre Andalucía y América. Sevilla, Fundación Buenas Letras, 2012, pp. 227-249.

Roos, M. A.: La producción cigarrera a finales de la Colonia. La Fábrica de México. México, INAH, 1983.

SAntamaría García, A.: «Reformas coloniales, economía y especialización productiva en Puerto Rico y Cuba, 1760-1850», Revista de Indias, 65:235, 2005, pp. 709-728.

SANTAmaría García, A. y GARcía Álvarez, A.: Economía y colonial. La economía cubana y la relación con España, 1765-1902. Madrid, Consejo Superior de Investigaciones Científicas, Instituto de Historia, Departamento de Historia de América, 2004.

STAPfF, A.: «La renta del tabaco en el Chile de la época virreinal. Un ejemplo de la política económica mercantilista», Anuario de Estudios Americanos 18, 1961, pp. 1-63.

SuÁrez ArgüEllo, C. E.: «De mercado libre a monopolio estatal: la producción tabacalera en Nueva España, 1760-1800», en Long Towell, J. y AtTolini Lecón, A. (coords.), Caminos y mercados de México. México, Instituto de Investigaciones Históricas de la Universidad Nacional Autónoma de México-Instituto Nacional de Antropología e Historia, 2009, pp. 411-432.

Torres, R.: «La política económica de la Renta del tabaco con el Secretario de Hacienda Miguel Muzquiz (1766-1785). La crisis de un sistema», en GonzÁlez Enciso, A. (ed.): Política económica y gestión de la Renta del Tabaco en el siglo XVIII. Madrid, Fundación Altadis, 2008.

Torres Ramírez, B.: «D. Jaime O’Daly: propulsor del cultivo del tabaco en Puerto Rico», Revista del Instituto de Cultura Puertorriqueña, 15, 1962, pp. 49-52.

Torres SÁnchez, R.: "Capitalismo internacional y política estatal. Los asientos del tabaco en España durante la segunda mitad del siglo xviII», en González Enciso, A. y Torres Sánchez, R. (eds.): Tabaco y Economía en el siglo XVIII. Pamplona, Eunsa, 1999, pp. 415-456.

Vizcarra, C.: Markets and Hierarchies in Late Colonial Spanish America: The Royal Tobacco Monopoly in the Viceroyalty of Perú 1752-1813. Tesis de doctorado, University of Illinois at Urbana-Champaing, 2001.

Whigham, T. L.: «Agricultura and the Upper Plata: the Tobacco Trade 1780-1865», Business History Review, 59:4, 1985, pp. 563-596.

Wortman, M. L.: Government and Society in Central American 1680-1840. Nueva York, Columbia University Press, 1982.

Zubiri MARIN, M. T.: «Un producto americano y su repercusión en la economía venezolana del s. XviII: el tabaco», Boletín Americanista, 1989, pp. 265-275. 
